CAHIER DE RECHERCHE \#1201E

Département de science économique

Faculté des sciences sociales

Université d'Ottawa
WORKING PAPER \#1201E

Department of Economics

Faculty of Social Sciences

University of Ottawa

\title{
News Shocks, Productivity and the U.S. Investment Boom-Bust Cycle
}

\author{
Lilia Karnizova*
}

January 2012

\footnotetext{
* Lilia Karnizova, Department of Economics, University of Ottawa, 55 Laurier Avenue East, Desmarais Building, Room 10121, Ottawa, Ontario, Canada, K1N 6N5. Tel.: 1-613-562-5800 x 2017. Fax: 1-613-562-5999. E-mail address: lilia.karnizova@uottawa.ca.
} 


\begin{abstract}
Overly optimistic expectations concerning productivity and consequent downward revisions are commonly viewed as a key determinant of U.S. investment during the boom-bust cycle of 19952003. This view is formalized and evaluated in a general equilibrium model with news shocks about future productivity and preferences for financial wealth. The model generates a boom-bust cycle in response to good news that is not realized. A method is devised to estimate "the productivity prospects": a series that captures the effects of news shocks on economic decisions. The estimated series rises during the boom, falls during the recession and helps forecast future productivity shocks at several horizons. The model's predictions for sample paths of hours worked, output, investment, consumption, wages and stock prices are largely in conformity with U.S. data. The model therefore offers a possible solution to several puzzles identified in the literature regarding the 1990's boom and the 2001 recession.
\end{abstract}

Key words: boom-bust cycles; news shocks; investment; expectations; preferences for wealth

JEL Classification: E21, E22, E27, E32.

\title{
Résumé
}

Les anticipations trop optimistes concernant la productivité et leur retournement substantiel sont généralement considérés comme un déterminant clé de l'investissement américain au cours du cycle d'expansion-récession de 1995-2003. Ce point de vue est formalisé et évalué dans un modèle d'équilibre général avec des chocs d'anticipations à propos de la productivité future et des préférences pour la richesse financière. Le modèle prédit un cycle d'expansion-récession en réponse à une bonne nouvelle qui n'est pas réalisée. Une méthode empirique est proposée afin de construire «des perspectives de productivité »: une série qui contient les effets des chocs d'anticipations sur les décisions économiques. La série estimée s'élève pendant la période du boom, chute durant la récession et prévoit des chocs de productivité réalisée sur plusieurs horizons. Les prédictions du modèle pour les sentiers d'heures travaillées, de production, d'investissement, de consommation, de salaires et de prix boursiers sont en grande partie conforment aux données américaines. Le modèle offre donc une solution possible aux caractéristiques inhabituelles identifiées dans la littérature concernant le boom des années 1990 et la récession de 2001.

Mots clés: le cycle d'expansion-récession; des chocs d'anticipations; l'investissement; des anticipations; des préférences pour la richesse

Classification JEL: E21, E22, E27, E32. 


\section{Introduction}

The U.S. economic boom in the 1990s and the recession that followed in 2001 were unusual in several ways. First, business fixed investment and hours worked grew rapidly in the 1990s. However, contrary to a common perception, measured real compensation per hour was below trend. McGrattan and Prescott (2010) showed that standard theories could not explain the boom in hours at the time of falling or low wages. Second, the 2001 recession was most likely triggered by a shock that caused an unexpected sharp decline in business investment. Such an investment-led recession is atypical of the postwar U.S. economy. Third, consumer spending diverged from its regular pattern. Despite the collapse of investment and the stock market crash, private consumption expenditures remained surprisingly strong throughout the recession and the recovery.

The unusual behavior of macroeconomic aggregates during the boom-bust cycle of 1995-2003 point to the uniqueness of the episode. A possible explanation of this uniqueness is the nature of shocks that hit the U.S. economy. Overly optimistic expectations and their consequent downward revisions are commonly viewed as a key determinant of business investment during that period. ${ }^{1}$ The idea is that anticipations of future technological advances increased expected returns to capital accumulation, which led to high levels of investment and to an economic boom. When the technology turned out to be not as productive as was expected, investment fell and a recession ensued. Despite the popularity of the 'expectation-revision' interpretation of the boom-bust cycle, it has not been formally examined in the literature. The present paper fills the gap.

The analysis is based on a spirit-of-capitalism (SOC) model with news shocks about future total factor productivity (TFP) studied by Karnizova (2010). A critical element of the model is direct preferences for financial wealth. These preferences capture the idea, proposed by Weber (1905), that wealth in a capitalist society can be accumulated not only for consumption purposes, but also for enhancing social status or even for its own sake. When consumption and financial wealth are sufficiently complementary, the model generates a boom-bust cycle in response to good news about TFP that is not validated in the future. The present paper extends the empirical analysis

\footnotetext{
${ }^{1}$ Appendix A contains several extracts from academic and government publications that discuss the distinct nature of the 2001 recession and that link the boom and the recession to a downward revision of optimistic expectations.
} 
of Karnizova (2010) by conducting a quantitative analysis of a particular historical episode.

Starting with the work of Beaudry and Portier (2004), a number of models have been developed to study the role of news in business cycles. ${ }^{2}$ The importance of news shocks has been judged by examining theoretical implications for statistical properties of fluctuations. No clear consensus has been reached on the relative contribution of TFP news shocks. For example, Beaudry and Portier (2004) and Jaimovich and Rebelo (2009) find that TFP news shocks are important in explaining business cycles, while Khan and Tsoukalas (2009) and Schmitt-Grohé and Uribe (2010) reach the opposite conclusion. The present paper contributes to the debate on the role of TFP news shocks by adopting an alternative evaluation strategy. It examines whether the SOC model with both news and surprise TFP shocks can predict booms, recessions and recoveries of the magnitude and duration observed in the U.S. data in the 1983-2010 period. The analysis of individual cycle enables one to focus on certain puzzles in the data, which may not be captured by conventional long-run statistics. Hansen and Prescott (1993), Xiao (2004), and McGrattan and Prescott (2010), among others, have used equilibrium models to evaluate possible causes of specific booms and recessions. The contribution of this paper is to show that the SOC model can provide a unified explanation for the unusual patterns of investment, consumption, hours worked and wages in the 1995-2003 period, mentioned above.

A novel method is devised to estimate empirical effects of news shocks. In the presence of news, forecasts of future productivity are based on the realized productivity and the expected future TFP impulses. A class of models with one endogenous state variable, to which the SOC model belongs, has a convenient representation. In this representation effects of news shocks on endogenous variables, that arise through the productivity forecasts, can be summarized by a single variable. This variable is equal to the discounted sum of expected future productivity impulses and is called 'the productivity prospects' in the paper. The proposed method estimates the productivity prospects by minimizing the distance between the actual U.S. data and the predicted equilibrium paths, while respecting cross-equation restrictions of the model.

The success of the SOC model at explaining the boom-bust cycle is judged by two criteria. Using

\footnotetext{
${ }^{2}$ Lorenzoni (2006) surveys the literature.
} 
the terminology of McGrattan and Prescott (2010), these criteria are called the input justification and the prediction criteria. The input justification criterion requires some evidence that the estimated productivity prospects capture TFP news shocks. The prediction criterion demands a conformity of the model's predictions to the U.S. time series. The SOC model satisfies both evaluation criteria.

This paper is complementary to Xiao (2004) and McGrattan and Prescott (2010) who also investigate the boom in the 1990s and the 2001 recession. Xiao (2004) focuses on sunspot shocks, or changes in expectations unrelated to economic fundamentals. He finds that these shocks may have been important in explaining U.S. investment and output. In contrast to Xiao (2004), the present paper evaluates the role of news shocks about future productivity. These shocks provide an alternative mechanism through which changes in expectations can affect the economy. In addition, the present paper evaluates the model's predictions for a broader set of variables.

McGrattan and Prescott (2010) argue that output and compensation were mismeasured in the 1990s because of intangible investment. They introduce intangible investment and non-neutral productivity change with respect to producing intangible investment into a standard real business cycle (RBC) model. Their model can simultaneously explain a surge in hours worked and a fall in measured compensation during the boom. The present paper proposes an alternative theory that abstracts from data mismeasurement. According to this theory, the boom in the late 1990s was driven by expectations of higher future productivity, at least partly. A news-driven boom in the SOC model arises primarily through the responses of labor supply, and the real wage is predicted to fall during the boom. The present paper also offers an explanation for the investment bust, which remains an unresolved puzzle in McGrattan and Prescott (2010).

The predictions for hours worked and wages differentiate the SOC model from the models of Beaudry and Portier (2004) and Jermann and Quadrini (2007). These models generate an economic boom in anticipation of future productivity gains. However, both models predict a simultaneous increase in hours and wages during the boom.

The rest of the paper is organized as follows. Section 2 specifies the model, describes the solution and its properties. Section 3 constructs the productivity shocks, calibrates the model 
and evaluates the role of the productivity changes. Section 4 describes the estimation of the productivity prospects, examines the resulting series and assesses the conformity of the model's predictions to the U.S. data. Section 5 discusses additional evidence related to the investment boom-bust cycle. Section 6 concludes.

\section{The spirit-of-capitalism model: description and solution}

This section describes a decentralized specification of the model and discusses its solution.

\subsection{The consumer's problem}

A representative consumer has the life-time utility defined over consumption $C_{t}$, the index of social status $X_{t}$ and hours worked $H_{t}$,

$$
\begin{gathered}
E_{t} \sum_{j=0}^{\infty} \beta^{j} U\left(C_{t+j}, X_{t+j}, H_{t+j}\right), 0<\beta<1, t \geq 0, \\
U\left(C_{t}, X_{t}, H_{t}\right) \equiv \frac{1}{1-\sigma}\left[(1-\omega) C_{t}^{\varphi}+\omega X_{t}^{\varphi}\right]^{\frac{1-\sigma}{\varphi}}-\eta_{t} H_{t}, \sigma>0,0<\omega<1, \varphi<1 .
\end{gathered}
$$

Here $E_{t}$ is the expectation conditional upon the information available in period $t$. Preferences for status relative to consumption are governed by $\omega$ and $\varphi$. A higher value of $\omega$ means a stronger status-seeking motive, and $1 /(1-\varphi)$ represents the elasticity of substitution between consumption and status. The value of $\sigma$ is related to the intertemporal elasticity of substitution. ${ }^{3}$ The parameter $\beta$ is the discount factor. To be consistent with balanced growth, preferences include the trend from the disutility of work, $\eta_{t}=\eta_{0} \Upsilon_{t}^{1-\sigma}, \eta_{0}>0$. The trend $\Upsilon_{t}$ is described below.

Status is defined as the value of financial assets held at the end of each period,

$$
X_{t} \equiv S_{t} \kappa_{t}
$$

Here $S_{t}$ is the period $t$ price of a claim to future profits of a representative firm, and $\kappa_{t}$ is the share of the firm owned by the consumer at the end of period $t$. Equating status with wealth is consistent with the 'absolute wealth is status' framework of Bakshi and Chen (1996).

\footnotetext{
${ }^{3}$ In this model, the elasticity is equal to $1 /\left\{\sigma+(1-\sigma-\theta) /\left[1+(1-\omega) / \omega /\left(C_{t} / X_{t}\right)^{\varphi}\right]\right\}$.
} 
The consumer chooses consumption, hours worked and asset holdings to maximize the lifetime utility subject to the definition of status and a sequence of budget constraints

$$
C_{t}+S_{t} \kappa_{t}=W_{t} L_{t}+\left(S_{t}+D_{t}\right) \kappa_{t-1}
$$

where $W_{t}$ is the hourly wage and $D_{t}$ is the dividends. The first order conditions are

$$
\begin{aligned}
-U_{L}\left(C_{t}, X_{t}, L_{t}\right) & =W_{t} U_{C}\left(C_{t}, X_{t}, L_{t}\right), \\
U_{C}\left(C_{t}, X_{t}, L_{t}\right) & =U_{X}\left(C_{t}, X_{t}, L_{t}\right)+\beta E_{t}\left[U_{C}\left(C_{t+1}, X_{t+1}, L_{t+1}\right) R_{t+1}\right],
\end{aligned}
$$

the budget constraints (3) and the transversality condition on asset holdings. The variable $R_{t+1} \equiv$ $\frac{S_{t+1}+D_{t+1}}{S_{t}}$ defines the market return from holding the firm for one period. The effective return, given by the right hand side of (5), includes the additional direct utility flows from higher wealth, through its effect on status.

\subsection{The firm's problem}

The representative, perfectly competitive firm owns the stock of capital $K_{t}$. Capital becomes productive after one period and depreciates at the rate $\delta, 0<\delta<1$. Installing new capital is subject to adjustment costs

$$
K_{t+1}=Q\left((1-\delta) K_{t}, I_{t}\right)=\left[g_{1}(1-\delta)^{\phi} K_{t}^{\phi}+g_{2} I_{t}^{\phi}\right]^{\frac{1}{\phi}}, t \geq 0
$$

with $\phi \leq 1, g_{1}>0, g_{2}>0$. No adjustment cost case corresponds to $\phi=1$, and $1 /(1-\phi)$ defines the elasticity of substitution between capital and investment. The initial capital stock $K_{0}$ is given.

Output $Y_{t}$ is produced using a Cobb-Douglas function with the capital share $\alpha$

$$
Y_{t}=F\left(K_{t}, A_{t} L_{t}, z_{t}\right) \equiv z_{t} K_{t}^{\alpha}\left(A_{t} H_{t}\right)^{1-\alpha}, 0<\alpha<1
$$

The variable $A_{t}=\gamma^{t}, \gamma>1$, represents a deterministic technological change. The productivity shock $z_{t}$, described below, captures stochastic changes in TFP.

The firm hires labor and makes investment to maximize its value to the owners. The firm does not issue new shares, and the amount of the existing shares is normalized to one. The period 
$t$ value of the firm is equal to the present value of its current and future dividends

$$
E_{t}\left(D_{t}+S_{t}\right)=D_{t}+E_{t} \sum_{j=1}^{\infty}\left(\prod_{m=1}^{j} \frac{1}{R_{t+m}}\right) D_{t+j}
$$

where $D_{t}=Y_{t}-W_{t} H_{t}-P_{t}^{I} I_{t}$ and $P_{t}^{I}$ is the price of investment in terms of consumption. Output is transformed into consumption and investment goods using a linear technology

$$
C_{t}+\frac{I_{t}}{V_{t}}=Y_{t}
$$

The investment specific technological change is deterministic, $V_{t}=\gamma_{v}^{t}, \gamma_{v}>1$, and reflects improvements in cost efficiency of producing investment relative to consumption goods.

Profit maximization implies

$$
\begin{aligned}
& F_{L}\left(K_{t}, A_{t} L_{t}, z_{t}\right)=W_{t} \\
& P_{t}=\frac{P_{t}^{I}}{Q_{2}\left((1-\delta) K_{t}, I_{t}\right)}, \\
& P_{t}=E_{t} \frac{1}{R_{t+1}}\left[F_{K}\left(K_{t+1}, A_{t+1} L_{t+1}, z_{t+1}\right)+(1-\delta) Q_{1}\left((1-\delta) K_{t+1}, I_{t+1}\right) P_{t+1}\right], \\
& P_{t}^{I}=V_{t}^{-1} .
\end{aligned}
$$

The variable $P_{t}$ is the current value Lagrange multiplier for the capital accumulation constraint. It represents the firm's internal shadow price of a unit of capital at the end of period $t$. Constant returns to scale in output production and capital adjustment costs imply that $P_{t}$ is equal to the present value of the expected future dividends per unit of capital,

$$
P_{t}=\frac{1}{K_{t+1}} \sum_{j=1}^{\infty}\left(\prod_{m=1}^{j} \frac{1}{R_{t+m}}\right) D_{t+j}=\frac{S_{t}}{K_{t+1}} .
$$

Thus, at an optimum the period $t$ market value of the firm is $S_{t}=P_{t} K_{t+1}$. 


\subsection{Productivity and news shocks}

The productivity shock $z_{t}$ evolves according to

$$
\begin{aligned}
\ln z_{t} & =\rho \ln z_{t-1}+\varepsilon_{t}, 0<\rho<1, \\
\varepsilon_{t} & =u_{t}+\xi_{t-1}^{1}+\xi_{t-2}^{2}+\ldots+\xi_{t-n}^{n}, n>0 .
\end{aligned}
$$

The innovations $u_{t}$ and $\xi_{t}^{j}$ are orthogonal to $\ln z_{t-m}, m>0 ; \quad E u_{t}=0$ and $E \xi_{t}^{j}=0$. These assumptions imply that the measured TFP impulse $\varepsilon_{t}$ is serially uncorrelated. The innovation $u_{t}$ is a 'surprise productivity shock', which has a contemporaneous effect on productivity. The innovation $\xi_{t}^{j}$ denotes the period $t$ 'news' or 'signal' about changes in the level of the productivity shock $j$ periods ahead. The shock specification allows modelling unfulfilled expectations. If a signal $\xi_{t-j}^{j}$ turns out to be incorrect, its value can be offset by the current realization of $u_{t}$.

It is common to assume that news shocks are uncorrelated with each other and with a surprise productivity shock. A notable exception is Christiano et al. (2010), who consider contemporaneously correlated news. The empirical identification in the present paper does not require an explicit assumption about the contemporaneous covariance structure of the shocks. In fact, the assumption of no correlation between $u_{t}$ and $\xi_{t}^{j}$ can be rejected based on the estimated productivity prospects.

Consumers and firms are assumed to know the true structure of the model and observe the current and past realizations of all shocks. They form optimal forecasts

$$
\begin{aligned}
E_{t} \ln z_{t+m} & =\rho^{m} \ln z_{t}+\sum_{j=1}^{m} \rho^{m-j} E_{t} \varepsilon_{t+j}, m>0, \\
E_{t} \varepsilon_{t+j} & =\sum_{i=j}^{n} \xi_{t+j-i}^{i} \text { for } 1 \leq j \leq n, E_{t} \varepsilon_{t+j}=0 \text { for } j>n .
\end{aligned}
$$

Standard real business cycle theory considers only surprise productivity shocks. In this case, $E_{t} \varepsilon_{t+j}=0$ for any $j>0$. The forecasts of future productivity are then completely determined by the realized values of the productivity shock $z_{t}$. With news shocks, the forecasts can be influenced by variables unrelated to the current productivity fundamentals. 


\subsection{Solution and its properties}

A rational expectations equilibrium is the sequences of prices $\left\{W_{t}, R_{t}, P_{t}, P_{t}^{I}, S_{t}\right\}_{t=0}^{\infty}$ and allocations $\left\{H_{t}, C_{t}, X_{t}, I_{t}, Y_{t}, K_{t+1}, D_{t}, \kappa_{t}\right\}_{t=0}^{\infty}$ such that (1) the allocations are optimal given the prices and (2) the markets for the goods and assets clear, given $K_{0}$ and the shock processes $\left\{z_{t}, \varepsilon_{t}, u_{t}, \xi_{t}^{1}, \ldots \xi_{t}^{n}\right\}_{t=0}^{\infty}$. In equilibrium, $\kappa_{t}=1$, and the market value of the capital stock determines status, $X_{t}=P_{t} K_{t+1}$. Hours worked and the asset return are covariance stationary. However, the behavior of other endogenous variables reflects time trends in neutral and investment-specific technology. To obtain a stationary representation, the equilibrium is expressed in terms of the following variables

$$
\begin{aligned}
& w_{t}=W_{t} / \Upsilon_{t}, r_{t}=R_{t}, p_{t}=V_{t} P_{t}, p_{t}^{I}=V_{t} P_{t}^{I}, s_{t}=S_{t} / \Upsilon_{t}, h_{t}=H_{t}, c_{t}=C_{t} / \Upsilon_{t} \\
& x_{t}=X_{t} / \Upsilon_{t}, y_{t}=Y_{t} / \Upsilon_{t}, i_{t}=I_{t} /\left(\Upsilon_{t} V_{t}\right), k_{t+1}=K_{t+1} /\left(\Upsilon_{t} V_{t}\right), d_{t}=D_{t} / \Upsilon_{t}
\end{aligned}
$$

where $\Upsilon_{t}=A_{t} V_{t}^{\alpha /(1-\alpha)}$. The model is solved numerically by applying Blanchard and Kahn (1980)'s algorithm to the log-linear approximation of the stationary representation around its unique deterministic steady state.

The solution in Blanchard and Kahn (1980)'s algorithm depends explicitly on the expected values of future productivity shocks. From the optimal forecasts (15)-(16), these values are determined by the realized productivity shock $z_{t}$ and by the news shocks $\xi_{t}^{j}$. Appendix B shows that the effects of the news shocks on the endogenous variables of the model, through their contributions to the productivity forecasts, can be summarized by the productivity prospects $\theta_{t}$. This variable is equal to the discounted sums of the expected future productivity impulses,

$$
\theta_{t} \equiv \sum_{j=1}^{\infty} \lambda^{-j} E_{t}\left(\varepsilon_{t+j}\right) .
$$

The discount factor $\lambda$ is the unstable eigenvalue of the model. The forecasts $E_{t} \varepsilon_{t+j}$ from (16) are linear functions of news shocks. For example, if $n=2$ and $\varepsilon_{t}=u_{t}+\xi_{t-1}^{1}+\xi_{t-2}^{2}$, then $\theta_{t}=\lambda^{-1}\left(\xi_{t}^{1}+\xi_{t-1}^{2}\right)+\lambda^{-2} \xi_{t}^{2}$.

Appendix $\mathrm{B}$ also derives an equilibrium path for any endogenous variable $v_{t}$ in terms of the 
capital stock, the realized productivity shocks and the productivity prospects

$$
\begin{aligned}
& \hat{k}_{t}=\hat{k}_{0}, t=0 \\
& \hat{k}_{t}=M_{k k} \hat{k}_{t-1}+M_{k z} \hat{z}_{t-1}+M_{k \theta} \theta_{t-1}, t>0, \\
& \hat{v}_{t}=M_{v k} \hat{k}_{t}+M_{v z} \hat{z}_{t}+M_{v \theta} \theta_{t}, t \geq 0 .
\end{aligned}
$$

The variables with the hats denote the percentage deviations from the steady state, $\hat{v}_{t}=\ln v_{t}-\ln v^{*}$. The coefficients $M_{i j}$ are non-linear functions of preference and productivity parameters, including the persistence of the productivity shock $\rho$. However, they are independent of the contemporaneous variance-covariance matrix of $u_{t}$ and $\xi_{t}^{j}, 1 \leq j \leq n$.

In the absence of news shocks, all future productivity impulses are unpredictable and $\theta_{t} \equiv 0$. Expectations about the future affect current decisions only through the realized productivity shock

$\hat{z}_{t}$. News shocks expand the influence of productivity fluctuations on economic behavior. Since the agents react to news shocks before these news shocks affect the productivity, changes in expectations receive an additional, independent role.

The solution (19) - (20) is valid for any value of the anticipation periods $n$. Christiano et al. (2010) describe how to construct a conventional state space representation of the model for a specific value of $n$. Finally, the following form of the solution is used in estimating $\theta_{t}$ :

$$
\begin{aligned}
\hat{k}_{t}\left(\hat{k}_{0}, \hat{\mathbf{z}}_{t-1}, \boldsymbol{\theta}_{t-1}\right) & =M_{k k}^{t} \hat{k}_{0}+M_{k z} \sum_{\tau=0}^{t-1} M_{k k}^{t-1-j} z_{\tau}+M_{k \theta} \sum_{\tau=0}^{t-1} M_{k k}^{t-1-j} \theta_{\tau}, t>0, \\
\hat{v}_{t}\left(\hat{k}_{0}, \hat{\mathbf{z}}_{t}, \boldsymbol{\theta}_{t}\right) & =M_{v k} \hat{k}_{t}\left(\hat{k}_{0}, \hat{\mathbf{z}}_{t-1}, \boldsymbol{\theta}_{t-1}\right)+M_{v z} \hat{z}_{t}+M_{v \theta} \theta_{t}, t \geq 0
\end{aligned}
$$

The vectors $\hat{\mathbf{z}}_{t} \equiv\left[\hat{z}_{0}, \ldots, \hat{z}_{t}\right]^{\prime}$ and $\boldsymbol{\theta}_{t} \equiv\left[\theta_{0}, \ldots, \theta_{t}\right]^{\prime}$ summarize the history of the realized productivity shocks and productivity prospects, and $\hat{k}_{0}$ is the initial stock of capital.

\section{Assessing the role of measured productivity changes}

This section examines whether the historical behavior of the U.S. economy can be explained by the observed productivity changes. Aggregate productivity is proxied by measured TFP. The SOC 
model is simulated with the productivity shocks and the counterfactual series are compared with the U.S. data. Given the history of the productivity shocks, the behavior of the U.S. economy during the 1995-2003 period is puzzling in several ways. These findings are consistent with the conclusions of Xiao (2004) and McGrattan and Prescott (2010), despite the differences in model specifications and data used.

\subsection{Construction of productivity measures and parameter calibration}

The sample covers the period from 1983:1 to 2010:4. The starting point reflects the beginning of an accelerated decline in the relative price of investment. It also captures the onset of the "Great Moderation", known as the period of the declined volatilities in major U.S. macroeconomic series. While the analysis of this paper centers on the boom-bust cycle of 1995-2003, the recessions of 1990-91 and 2007-2009 are included for comparison.

Identification of productivity shocks The TFP estimate is computed from the production function, $\mathrm{TFP}_{t} \equiv Y_{t} K_{t}^{-\alpha} H_{t}^{\alpha-1}$. The data on output and inputs are for the nonfarm business sector. Output is measured by the value added quantity index from the Bureau of Economic Analysis (BEA). Hours worked are from the Bureau of Labor Statistics (BLS). Capital input is based on the BLS annual series for capital services. The annual series is converted to quarterly by assuming a constant growth rate within each quarter. The value of $\alpha$ is 0.32 , which is the average capital's share in total costs over the sample period. ${ }^{4}$ The TFP index is normalized to 100 in 2005.

The trend $A_{t}$ and the shock $z_{t}$ are estimated from the relation $\mathrm{TFP}_{t}=z_{t} A_{t}^{1-\alpha}$. Since the productivity impulse $\varepsilon_{t}$ is serially uncorrelated, the logarithm of the productivity shock $z_{t}$ is characterized by the first order autoregressive process. The resulting point estimates are $\gamma=1.0044$, $\rho=0.9071$ and $\sigma_{\varepsilon}=0.0064$.

Identification of investment technology The investment-specific technology's trend is estimated from the inverse of the relative price of investment, as implied by (11). The relative price is measured by a ratio of the chained price indices for the total private fixed investment and total private consumption. The point estimate for $\gamma_{v}$ is 1.0032 .

\footnotetext{
${ }^{4}$ The data sources are described in Appendix C.
} 
Improvements in the investment-specific technology make investment goods cheaper relative to consumption goods. A declining cost of investment should stimulate investment purchases. A secular trend in the investment prices during the sample period is believed to capture the firstorder effect of the investment-specific technology on growth differences between consumption and investment. Given the productivity parameters, the model predicts the average annual growth rate of 2.36 percent for consumption and output, and of 3.64 percent for investment.

Calibration of non-productivity parameters The rest of the parameters are assigned as follows. As in King and Rebelo (1999), the rate of capital depreciation is $\delta=0.025$, the parameter $\eta_{0}$ is chosen so that the consumer works twenty percent of the available time in the steady state, and the discount factor $\beta$ is calibrated to get the steady state quarterly rate of return to capital of 1.625 percent. The parameters $g_{1}$ and $g_{2}$, are chosen to make the steady state independent of the degree of capital adjustment costs. The values $\sigma=0.185, \varphi=-0.606, \omega=0.83$ and $\phi=0.802$ are from Karnizova (2010). These parameters were estimated to match a number of empirical moments of the U.S. data under the assumptions that the productivity impulses could be anticipated four periods in advance, $\varepsilon_{t}=u_{t}+\xi_{t-4}^{4}$ and that the productivity shock followed an autoregressive process (13) with the values of the persistence 0.979 and the standard deviation of $\varepsilon$ of 0.0072 from King and Rebelo (1999).

\subsection{Results}

Figure 1 displays the empirical series for TFP and the productivity shocks. The measured productivity is below the trend most of the 1990s, as in McGrattan and Prescott (2010). This feature implies that a productivity-based model will likely have a problem explaining the economic boom during that period. The measured TFP used by Xiao (2004) is above the trend. However, his series is based on the productivity data that were subsequently revised downward. Section 4.2.3 provides additional information about the data revisions.

Panel $\mathrm{C}$ of Figure 1 plots the series for measured TFP impulses $\varepsilon_{t}$. There are adverse productivity shocks during each recessionary episode in the sample, which allows for the possibility that these shocks triggered the recessions. Panel $\mathrm{C}$ also displays technology shocks reported by 
Ireland (2011). This series is derived with the Kalman filter based on a New Keynesian model. Notably, the two different approaches to constructing productivity shocks produce similar estimates.

Prior to analyzing the simulation results, it is useful to examine how the model economy reacts to a surprise TFP shock. Figure 2 traces out the impulse responses to an unexpected productivity shock $u_{t}$. For clarity of presentation, this shock is assumed to be orthogonal to all news shocks $\xi_{t}^{j}$. A surprise positive productivity shock, observed in period one, creates an economic boom in hours worked, output, investment and consumption. It also raises the real wage and the price of capital. Conversely, an adverse productivity shock leads to a recession. Figure 2 also illustrates that the responses of the SOC model are similar to the predictions of a RBC model that abstracts from status $(\omega=0)$. This RBC specification retains the values for $\sigma$ and $\phi$, and follows the same calibration in selecting the parameters $\beta$ and $\eta_{0}$.

To assess the role of productivity changes, the SOC model is simulated with the estimated productivity shocks. In this section, the productivity prospects are zero $\left(\theta_{t} \equiv 0\right)$. The simulation runs from 1983:2 to 2010:4. The initial capital stock $\hat{k}_{0}$ is set to the deviation of the capital services from the linear trend in 1983:2. The resulting value is $\hat{k}_{0}=-0.0133$.

The counterfactual and actual series are plotted in Figures 3 and 4 . Output and hours are for the nonfarm business sector, as was indicated earlier. Consumption and investment are measured by the BEA's chained quantity indexes for private aggregate consumption and private fixed investment. All series are converted to per-capita terms using the civilian noninstitutional population over 16 years old. Figure 3 plots the data for the whole sample. Hours worked are expressed in percentage deviations from the mean. The other series are plotted in levels, normalized to 100 in 1983:2. Figure 4 focuses on the recessionary episodes. All series in Figure 4 are expressed as percentage changes from the level reached at the previous NBER cyclical peak.

The productivity-based SOC model fails to account for the boom in hours worked, output, investment and consumption in the late 1990s. Given that the measured TFP was below the trend, the model predicts a depressed economy. The counterfactual prediction does not rely on the presence of wealth in the utility function. McGrattan and Prescott (2010) obtain the same result in a standard RBC model. Further, McGrattan and Prescott (2009) show that augmenting the 
standard model with stochastic changes in the investment-specific technology and variable labor tax rates is not sufficient to explain the U.S. boom in the 1990s.

The SOC model correctly predicts the recessions in 1990-91 and 2007-09. The counterfactual and actual hours, output, investment and consumption, plotted in Figure 4, decline by the similar magnitudes. However, the model overpredicts the speed of the recoveries. The results are somewhat reminiscent of the conclusions reached by Ireland (2011) regarding the impact of technology shocks on real GDP.

There is a striking difference between the predicted and actual paths for hours, output, investment and consumption during and after the 2001 recession. Given the productivity measures, the U.S. economy should have been growing in 2001-2003. Xiao (2004) and McGrattan and Prescott (2010) reach similar conclusions: productivity-based models fail to predict the 2001 recession.

The 2001 recession is puzzling not only from a theoretical perspective. The investment bust and the recession caught many contemporaneous observers by surprise. Based on the analysis of real-time forecasts, Kliesen (2003) and Stock and Watson (2003) concluded that even professional forecasters had difficulties recognizing the onset and the duration of the recession. The forecasting performance of leading indicators during the 2001 recession differed from the preceding recessions. These differences could be attributed, at least partly, to the distinct nature of the recession itself. The rest of the paper demonstrates that the revisions of optimistic expectations may account for the unique features of the investment boom-bust cycle in the 1995-2003 period.

\section{Assessing the role of news shocks}

This section first shows that the SOC model predicts a boom-bust cycle in response to good news about future TFP that is not validated in the future. Then it describes the estimation approach to identify the productivity prospects and analyzes the resulting estimates. Finally, the section compares the model's predictions for aggregate quantities and prices with the U.S. data. 


\subsection{News-driven boom-bust in the SOC model}

The SOC model economy can go through a boom-bust cycle driven purely by changes in expectations. Figure 5 provides an illustration. It plots the impulse responses to an announcement, received in period one, that the log-level of the productivity shock will be one percent higher in period ten. In period ten, however, there is no change in productivity.

Hours, output, investment, consumption and the price of capital all rise during the boom. Labor demand, determined by (8), is not directly affected by news shocks. However, labor supply, given by (4), increases. Since the boom is mainly driven by an expansion of labor supply, the real wage falls. When no productivity change is observed in period ten, the economy has an oversupply of capital. Hours, output, investment and the price of capital fall sharply. Consumption falls gradually. As capital depreciates, the economy converges back to its steady state.

The simultaneous increase in hours, output, investment, consumption and the price of capital in response to a news shock is difficult to obtain in many standard models. ${ }^{5}$ For example, the RBC model that abstracts from status predicts a fall in consumption. The complementarity between consumption and status, and a variable price of capital are critical to generate a boom in the SOC model. Karnizova (2010) explains that preferences for financial wealth, that arise through status, magnify the incentives to save and work. If the wealth is valued sufficiently, taking leisure becomes costly when the return on capital accumulation is high. At the same time, higher wealth raises the value of current consumption and stimulates consumer spending. Thus, households choose to work, consume and invest more in response to an exogenous change in expectations.

\subsection{Identification of the productivity prospects}

News shocks cannot be directly estimated from the productivity shocks described by (13)(14). However, news shocks change the productivity forecasts and affect the behavior of consumers and firms. Thus, the observed economic series should help identify latent news shocks. The proposed identification method effectively answers the following question: "What process for the productivity prospects $\theta_{t}$ brings the predicted sample paths for hours worked, output, investment

\footnotetext{
${ }^{5}$ See Beaudry and Portier (2007), Jaimovich and Rebelo (2009), Christiano et al. (2008).
} 
and consumption as close as possible to the actual U.S. data if the consumers and firms in the SOC model are faced with the measured TFP?".

\subsubsection{Estimation approach}

The identification starts with an assumption that the SOC model provides a reasonable approximation of the data. Let $\tilde{v}_{t}$ (data) denote an empirical analogue of a theoretical variable $\hat{v}_{t}$, expressed as the percentage deviations from the steady state. It is assumed that the observed empirical series is a noisy indicator of its true theoretical counterpart,

$$
\tilde{v}_{t}(\text { data })=\hat{v}_{t}\left(\hat{k}_{0}, \hat{\mathbf{z}}_{t}, \boldsymbol{\theta}_{t}\right)+e_{v, t} .
$$

The error term $e_{v, t}$ captures errors due to data measurement or abstractions of the model.

In Section 3, the SOC model was simulated with the measured productivity shocks, starting from the initial value of the capital stock in 1983:02. Conditional on the same values of $\hat{z}_{t}$ and $\hat{k}_{0}$, the difference between the equilibrium paths of the model with and without the productivity prospects is attributed to the effects of the unobserved productivity prospects. More specifically, the solutions (21) and (22) imply

$$
\begin{aligned}
& \hat{v}_{t}\left(\hat{k}_{0}, \hat{\mathbf{z}}_{t}, \boldsymbol{\theta}_{t}\right)-\hat{v}_{t}\left(\hat{k}_{0}, \hat{\mathbf{z}}_{t}, 0\right)=M_{v k} M_{k \theta} \sum_{\tau=0}^{t-1} M_{k k}^{t-1-j} \theta_{\tau}+M_{v \theta} \theta_{t} \\
= & M_{v k} M_{k \theta}\left[M_{k k}^{t-1} \theta_{0}+M_{k k}^{t-2} \theta_{1}+\ldots+M_{k k}^{-1} \theta_{t-2}+\theta_{t-1}\right]+M_{v \theta} \theta_{t}
\end{aligned}
$$

Based on the expressions (23) and (24), the difference between the empirical series $\tilde{v}_{t}$ (data) and the predicted series $\hat{v}_{t}\left(\hat{k}_{0}, \hat{\mathbf{z}}_{t}, 0\right)$ from section 3 should convey information about the unobserved productivity prospects. That is,

$$
\tilde{v}_{t}(\text { data })-\hat{v}_{t}\left(\hat{k}_{0}, \hat{\mathbf{z}}_{t}, 0\right)=M_{v k} M_{k \theta} \sum_{j=0}^{t-1} M_{k k}^{t-1-j} \theta_{j}+M_{v \theta} \theta_{t}+e_{t}^{v}
$$

Consider a sample with $T$ observations and let $\hat{\mathbf{z}}(T) \equiv\left[\hat{z}_{0}, \ldots, \hat{z}_{T-1}\right]^{\prime}$ and $\boldsymbol{\theta}(T) \equiv\left[\theta_{0}, \ldots, \theta_{T-1}\right]^{\prime}$ denote the history of the realized values from $t=0$ to $T-1$. Further, let $\tilde{v}(T)-\hat{v}(T, 0) \equiv$ 
$\left[\tilde{v}_{0}(\text { data })-\hat{v}_{0}\left(\hat{k}_{0}, \hat{\mathbf{z}}_{0}, 0\right), \ldots, \tilde{v}_{T-1}(\text { data })-\hat{v}_{T-1}\left(\hat{k}_{0}, \hat{\mathbf{z}}_{T-1}, 0\right)\right]^{\prime}$ and $\mathbf{e}^{v}(T)=\left[e_{0}^{v}, \ldots, e_{T-1}^{v}\right]^{\prime}$. The difference between the two vectors is

$$
\tilde{v}(T)-\hat{v}(T, 0)=\mathbf{A}_{v} \boldsymbol{\theta}(T)+\mathbf{e}^{v}(T)
$$

where the matrix $\mathbf{A}_{v}$ has the following structure

$$
\mathbf{A}_{v}=M_{v k}\left[\begin{array}{cccccc}
\varphi_{v} & 0 & 0 & \vdots & 0 & 0 \\
1 & \varphi_{v} & 0 & \vdots & 0 & 0 \\
M_{k k} & 1 & \varphi_{v} & \vdots & 0 & 0 \\
\ldots & \ldots & \ldots & \vdots & \ldots & \ldots \\
M_{k k}^{T-3} & M_{k k}^{T-4} & M_{k k}^{T-5} & \vdots & \varphi_{v} & 0 \\
M_{k k}^{T-2} & M_{k k}^{T-3} & M_{k k}^{T-4} & \vdots & 1 & \varphi_{v}
\end{array}\right], \varphi_{v} \equiv M_{v \theta} / M_{v k}
$$

It is critical that all coefficients in $\mathbf{A}_{v}$ are functions of the parameters assigned during the calibration. The period $t$ productivity prospects $\theta_{t}$ has a level effect on the values of $\tilde{v}_{t}($ data $)-\hat{v}_{t}\left(\hat{k}_{0}, \hat{\mathbf{z}}_{t}, 0\right)$ from the period $t$ forward.

The expression (25) is valid for any endogenous variable of the model. The series on hours worked, output, investment and consumption are used in the estimation,

$$
\left[\begin{array}{c}
\tilde{\mathbf{h}}(T)-\hat{\mathbf{h}}(T, 0) \\
\tilde{\mathbf{y}}(T)-\hat{\mathbf{y}}(T, 0) \\
\tilde{\imath}(T)-\hat{\imath}(T, 0) \\
\tilde{\mathbf{c}}(T)-\hat{\mathbf{c}}(T, 0)
\end{array}\right]=\left[\begin{array}{c}
\mathbf{A}_{h} \\
\mathbf{A}_{y} \\
\mathbf{A}_{i} \\
\mathbf{A}_{c}
\end{array}\right] \boldsymbol{\theta}(T)+\left[\begin{array}{c}
\mathbf{e}^{h}(T) \\
\mathbf{e}^{y}(T) \\
\mathbf{e}^{i}(T) \\
\mathbf{e}^{c}(T)
\end{array}\right] .
$$

While the vector $\boldsymbol{\theta}(T)$ is unobserved, the matrices $\mathbf{A}_{v}$ are known. The model (27) defines a generalized regression with $T$ regression coefficients $\left\{\theta_{0}, \theta_{1}, \ldots, \theta_{T-1}\right\}$. The productivity prospects in period $t(t=0, \ldots, T)$ are equated to the $(t+1)^{\text {th }}$ regression coefficient. The residuals $\mathbf{e}(T)$ are assumed to be zero mean, heteroscedastic, uncorrelated with each other at all lags, but autocorrelated with a common coefficient. Formally, $E\left(e_{t}^{v}\right)=0, E\left(e_{t}^{v}\right)^{2}=\sigma_{v}^{2}, E\left(e_{t}^{v} e_{t-1}^{v}\right)=\rho_{e}$, $E\left(e_{t}^{v} e_{t-j}^{\varkappa}\right)=0$ for any $j$ and $v, \varkappa \in\{h, y, i, c\}$.

The estimation period runs from 1983:2 to 2010:4. There are 444 observations. The empirical analogues of the model's deviations from the steady state, $\tilde{v}_{t}$ (data), are constructed by detrending 
the levels of per capita series with the trends implied by the SOC model and then removing the means computed over the whole sample. The estimated coefficients include 111 parameters for $\theta_{t}$, a common autocorrelation coefficient $\rho_{e}$, and four parameters in the covariance matrix. A pooled regression model (27) is estimated by the feasible generalized least squares using the xtgls procedure in STATA. The resulting point estimates for the error terms are $\rho_{e}=0.9886$, $\sigma_{h}=0.0049, \sigma_{y}=0.0033, \sigma_{i}=0.0033$ and $\sigma_{c}=0.0061$.

\subsubsection{Results: estimates of productivity prospects}

Figure 6 plots the point estimates of the productivity prospects along with the 95-percent asymptotic confidence intervals. Given the definition (18), a positive value of $\theta_{t}$ reflects an expectation that future productivity will exceed the forecast based on the historical productivity shocks alone. Similarly, a negative value of $\theta_{t}$ indicates that future productivity will fall below the TFPbased forecast. Expectations become more optimistic (pessimistic) between any two periods if the values of the productivity prospects increase (decline).

The estimated productivity prospects assign a relatively unimportant role to news shocks in the first third of the sample, when the estimated values of $\theta_{t}$ are positive, but marginally significant. The productivity prospects rise gradually from 1993 until 2000. During the 2001 recession and the subsequent two years the productivity prospects fall sharply. Another sharp decline in the productivity prospects occurs between 2009 and 2010.

\subsubsection{Interpretation of the productivity prospects}

The productivity prospects are constructed as an unobserved measure that minimizes the difference between the actual and predicted quantities, while respecting the cross-equation restrictions of the SOC model. The estimated series can, in principle, reflect effects of omitted shocks. This subsection examines the validity of the "news" interpretation of $\theta_{t}$ in several ways. First, it compares the estimated series with other observed measures of expectations. Second, it reviews the TFP forecasts from the Congressional Budget Office (CBO). Finally, it investigates the empirical relation between the productivity prospects and the measured productivity impulses. 
Comparison with observed measures of expectations Panel B of Figure 6 plots the estimated productivity prospects along with two direct, survey-based measures of expectations: the Gallup index of investor optimism and the University of Michigan's index of consumer sentiment. To facilitate the comparison, all three indexes are demeaned and divided by their standard deviations. The behavior of the three measures is remarkably similar. For the whole sample period, the correlation coefficients are 0.70 for the productivity prospects and the consumer confidence index, and 0.80 for the productivity prospects and the investor confidence index. The similarity is even stronger during the investment boom-bust cycle.

Evidence from TFP forecasts TFP projections are a key input in 10-year projections of real output produced by the Congressional Budget Office. Table 2 reports the projected average annual growth rate of potential TFP for the nonfarm business sector published in various issues of The Budget and Economic Outlook from 1998 to 2009. In making its projections, the CBO focuses on a medium-term trend and abstracts from forecasting cyclical movements beyond two years. Nevertheless, the CBO publications give an interesting account of the historical revisions of the real-life TFP forecasts.

From August 1998 to January 2011, the projected TFP growth over the 10-year horizon was gradually revised upward, with a total of 0.6 percentage points. The $\mathrm{CBO}$ estimates that a tenth of a percentage point increase in the TFP growth, accumulated over the ten years, would raise the level of real GDP by roughly one percent, or about $\$ 200$ billion (Congressional Budget Office (2005, p. 27)). From August 2001 until August 2003, the average projected TFP growth was revised down by 0.3 percentage points. Explanatory notes for the projection numbers link the revisions to new data releases, the CBO's assumptions on whether the observed productivity changes are temporary or permanent, and methodological changes in estimating the TFP growth.

The CBO reports not only the projected, but also the actual growth rate of potential TFP over various periods. The TFP estimates for the late 1990s were lowered significantly following the revisions to real GDP, capital and labor inputs released by the BEA and the BLS in 2001 and 2004. For example, the CBO estimated the average annual TFP growth rate for the 1995-99 period to be 1.7 percent in January 2000. This growth rate was down to 1.3 percent in 2005 . The 
"cumulative effect of all of the revisions was to lower the level of TFP by 2 percent in 1999" (Box 2-1, Congressional Budget Office (2005, p. 29)).

The CBO's estimates of the annual growth rate of potential TFP are not directly comparable with the values of the productivity prospects. Yet, changes in the CBO's estimates point to a rise and fall of the expected TFP growth during the investment boom-bust cycle.

Testing the relation between the productivity prospects and productivity impulses To be consistent with the news shocks interpretation, the values of $\theta_{t}$ must be able to predict some future realizations of the productivity impulses. Figure 7 plots the correlations between the measured productivity impulses $\varepsilon_{t}$ and the first difference of the estimated productivity prospects $\Delta \theta_{t+j}$ against $j$. The first difference is chosen because a unit root in the level of $\theta_{t}$ cannot be rejected. The correlation between $\varepsilon_{t}$ and $\Delta \theta_{t+j}$ for $j<0$ indicates that changes in $\Delta \theta_{t}$ lead changes in the measured productivity impulse. A null hypothesis of no correlation between $\varepsilon_{t}$ and any lags of $\Delta \theta_{t}$ from one to thirty cannot be rejected at the six percent significance level. This conclusion is based on the $p$-value of the Ljung-Box $Q$ statistics, reported in the bottom left corner of Figure 7 .

The predictive power of $\Delta \theta_{t}$ is further assessed with the forecasting equation

$$
\varepsilon_{t}=a_{0}+b_{j} \Delta \theta_{t-j}+e_{t}^{\varepsilon}, j=1, \ldots, 30,
$$

where the error term is assumed to be serially uncorrelated with zero mean. The absence of news shocks corresponds to the null hypothesis that $b_{j}=0$ for all $j>0$. Table 2 reports the regression coefficients, their $p$-values and the $\bar{R}^{2}$ statistics for the lags $j$, for which the null hypothesis of no news can be rejected. The regression results imply that the realizations of the productivity impulses $\varepsilon_{t}$ are forecastable about two, five and six years ahead. Further, changes in $\theta_{t}$ can explain from two to almost ten percent of the variation in the future values of the productivity impulses. Table 2 indicates that the predictability results also hold for the 1983:2-2007:2 sample.

It should be noted that the estimates of $\theta_{t}$ are obtained without an explicit assumption about the contemporaneous covariance structure of the news shocks. If for all $1 \leq j \leq n$, the news $\xi_{t}^{j}$ are uncorrelated with each other and with $u_{t}$, then the definitions (14) and (18) imply that the current value of $\varepsilon_{t}$ should be uncorrelated with any future values of $\Delta \theta_{t}$. Based on the Ljung-Box $Q$ statistics reported in the right corner of Figure 7, a null hypothesis of no correlation of $\varepsilon_{t}$ with 
any $\Delta \theta_{t+j}$ for $j$ from one to thirty is strongly rejected. This result supports an argument raised by Leeper and Walker (2011) regarding exploring alternative specifications of news processes and letting data choose among the alternatives.

\subsubsection{Relation to other methods of identification of news shocks}

The identification method constructs a measure of the productivity prospects, defined by (18). This measure accumulates the contributions of news shocks to the productivity forecasts. The method cannot identify individual realizations of news shocks $\xi_{t}^{j}$ without some additional assumptions about the number of anticipation periods $n$ and the covariance structure of news shocks.

Two alternative approaches to identification of news shocks exist in the literature. The first approach is based on structural vector autoregressions or structural vector error correction models that include TFP series. ${ }^{6}$ Similar to this approach, the proposed identification method relies on the empirical TFP. It imposes more restrictions on the data, since it is based on a fully specified general equilibrium model. However, the method is not limited to working with invertible models.

The second approach relies on an equilibrium model estimation. ${ }^{7}$ This approach imposes particular assumptions about the number of news shocks, the number of anticipation periods and the covariance structure of shocks. The series of news shocks can, in principle, be constructed within this approach by using the Kalman smoother. To my best knowledge, none of the existing studies reports the implied TFP news shocks.

\subsection{Comparison of the predicted and the actual data}

This section compares the U.S. data with the counterfactuals predicted by the SOC model simulated with the productivity shocks and the estimated productivity prospects. The simulation starts with the same capital stock as in section 3, and runs from 1983:2 to 2010:4. The model's predictions are evaluated for two sets of variables. Hours worked, output, investment and consumption are used in estimating the productivity prospects. A test of internal consistency requires

\footnotetext{
${ }^{6}$ Beaudry and Portier (2006), Beaudry and Lucke (2010), Barsky and Sims (2011), Kurmann and Otrok (2011).

${ }^{7}$ Schmitt-Grohé and Uribe (2010), Khan and Tsoukalas (2009), Christiano et al. (2010).
} 
that the counterfactual and actual paths for aggregate quantities are close to each other. A test of external consistency evaluates the predictions for wages and stock prices.

\subsubsection{Results: internal consistency of the model}

The counterfactual and actual U.S. data for hours worked, output, investment and consumption are plotted on Figures 3 and 4. Even though the quantity series are used in estimating the productivity prospects, the perfect fit between data and theory is not guaranteed. The productivity prospects is the only free series in matching four quantity series.

The SOC model with the productivity prospects can explain several observations that are puzzling from the perspective of the productivity-driven model. First, it correctly predicts a boom in hours, output, investment and consumption in the late 1990s. Second, the model economy has a recession in 2001. Third, the decline in hours and investment during and after the 2001 recession is of the similar magnitude and duration as in the data. Fourth, the predicted path for output

conforms to the actual. Finally, consumption grows during and after the 2001 recession, despite the fall in investment and hours. By contrast, both counterfactual and actual consumption fall during the 1990-91 and the 2007-09 recessions. However, the model overpredicts the strength of consumer spending during the 2001 recession.

A possible limitation of the analysis is the use of the revised data. The model assumes that the realized productivity shocks are observed and that the TFP process is known. However, the TFP series for the 1995-2000 period were substantially revised later, and these changes were unanticipated. If the initial estimates were treated as true realizations by consumers and firms, the economic boom could have been partly explained by productivity changes. Thus, the importance of the productivity prospects may be overestimated.

Xiao (2004) uses TFP series that do not reflect the subsequent downward revisions. His results show that a productivity-driven model fails to account for the magnitude of the boom in the 1990s and the occurrence of the 2001 recession. Optimistic expectations of future productivity and their revisions would have still likely remained important during the boom-bust cycle even if the real-life data were used in the analysis. 


\subsubsection{Results: external consistency of the model}

The predictions of the SOC model are now examined for real wages and stock prices. This test of external consistency is demanding for three reasons. First, the prices are not used in estimating the productivity prospects. Second, the joint behavior of hours worked and wages is considered unusual during the boom in the 1990s. Finally, many real business cycle models have difficulty in explaining price behavior. ${ }^{8}$

The wage rate is measured by the BLS real hourly compensation for nonfarm business sector. The stock price is the S\&P500 index divided by the consumption price index. Detrending the prices with the trends in (17) left visible trends. Therefore, the prices are expressed in percentage deviations from their own linear trends computed over the whole sample period.

The real wage and the boom-bust cycle McGrattan and Prescott (2010) emphasize one puzzling aspect of the boom in the 1990s: a surge in hours worked occurred at the time when real wages were low relative to the long-run trend. Neither the RBC nor the SOC model with only productivity shocks can resolve the puzzle. Both models predict a positive comovement of hours and the real wage in response to a surprise productivity shock, as shown on Figure 2. The counterfactual paths of hours and the real wage, plotted on Figures 3 and 8, are below the steady state in the late 1990s.

The SOC model with the productivity prospects provides a possible explanation for the joint behavior of hours and wages. The model generates a news-driven boom through an expansion of labor supply. As a result, hours worked and the wage rate are negatively correlated during the expectation-driven boom, as the impulse responses on Figure 5 illustrate. The counterfactual hours on Figure 3 are booming in the late 1990s, while the real wage on Figure 8 is below the trend. Even though the SOC model cannot account for the behavior of wages completely, the counterfactual and actual series are positively correlated. The correlation is 0.60 for the whole sample, and 0.77 for the 1995:01-2003:04 period.

How plausible is the adjustment mechanism of the SOC model? The direct preferences for financial wealth strengthen a link between labor supply decisions and changes in the stock market. A large proportion of U.S. workers receive "shared capitalism" compensation, including profit

\footnotetext{
${ }^{8}$ See, for example, Christiano and Eichenbaum (1992) and Jermann (1998).
} 
sharing, bonuses, ownership of shares and broad-based stock options. ${ }^{9} \quad$ One of the key reasons for adopting shared compensation is a belief that it will "boost productivity by raising workers' incentives to work harder and smarter" (Lebow et al. (1999, p. 10)).

Employee ownership of shares and stock options is particularly interesting for the SOC model because it directly relates worker pay to a company's stock market performance. Himmelberg et al. (2004) find that the exercise of employee stock options grew very rapidly between 1996 and 2001. McGrattan and Prescott (2010) document that the increase in hours during the boom in the 1990s was largely concentrated in industries and occupations related to information technology (IT). The increase in hours was closely linked to the increase in business capital gains. However, the average growth of median earnings of the IT workes was the same as for all workers. McGrattan and Prescott (2010, p. 89) interpret the increase in uncompensated business hours as a form of intangible investment, "made with the expectation of realizing future profits or capital gains when the business goes public or is sold".

The present paper does not model stock options explicitly. Yet, changes in the stock market have a direct positive effect on labor supply. This effect arises through the preferences for social status, which in equilibrium is equal to the market value of the firm. By contrast, changes in the stock market affect labor supply only through changes in consumption in a RBC model with conventional preferences. ${ }^{10}$

Stock prices and the boom-bust cycle The stock price in the SOC model corresponds to the implicit price of capital $P_{t}$, defined by (12). Figure 5 shows that this price rises then falls during an expectation-driven boom-bust cycle. The predicted values for $\hat{p}_{t}$ on Figure 8 are multiplied by a factor of ten because the SOC model underpredicts the empirical stock price volatility. The model with the productivity prospects does capture the direction of stock price changes in the data. The correlation between the counterfactual and actual series is 0.63 for the whole sample and 0.90 for the 1995:01-2003:04 period. By contrast, the same correlation is 0.11 and -0.04 for the SOC model with only productivity shocks.

\footnotetext{
${ }^{9}$ See, for example, Lebow et al. (1999), Freeman (2008) and Kruse et al. (2008).

${ }^{10}$ Section 4.1 in Karnizova (2010) provides additional explanations.
} 


\section{Other evidence in support of the expectation revision story}

This section reviews additional evidence consistent with the view that the boom-bust cycle may have resulted from a re-evaluation of optimistic expectations about future productivity. This evidence gives some hints on potential determinants of the productivity expectations.

Data revisions Measurement errors may explain why the productivity forecasts in the late 1990s appear overly-optimistic in light of the revised data. The BEA and the BLS released a number of updates for the 1995-2000 period between 2001 and 2004. The revised statistics lowered the pace of the U.S. economy relative to the initial estimates. Among the most significant updates were revisions of U.S. corporate profits reported in the NIPA. The profits summarize the assessment of the current state and future prospects of the corporate sector. The profitability turned out to be substantially weaker than "real-time" data indicated. According to the computations in Himmelberg et al. (2004), the downward revisions to the one-year growth rate of corporate profits of 12.0 percent for 1998 and 11.4 percent for 2000 were unusually large and diverging from the preceding trend of upward revisions.

Investment and earnings The shift is expectations can be seen in the behavior of long-term earnings forecasts, and its relation to investment and realized earnings. Jaimovich and Rebelo (2009) analyze the data for the companies in the S\&P500 index. The earnings forecast rises rapidly from 1995 to 2001 and then falls until 2004. The realized earnings follow a different pattern. Interestingly, investment is positively correlated with the earnings forecast, but negatively correlated with the realized earnings. For the 1995-2004 period, the corresponding correlation coefficients are 0.71 and -0.46 .

The telecom boom-bust cycle The telecommunications sector is an example of an industry that experienced a boom-bust cycle in investment, employment, production and stock prices during the period from 1996 to 2002. Couper et al. (2003) analyze the industry in detail, and conclude that the telecom boom and bust was caused by changes in the regulatory environment and rapid technological progress. In particular, Couper et al. (2003) document the rise and fall of optimism related to the 1996 Telecommunications Act and to the implications of the increased capacity of 
fiber glass and wireless networks to transmit data.

The impact of the Internet One rationale for modelling news shocks is a gradual diffusion of new technology. The increased use of computers and the Internet in the 1990s gave a rise to the notion of a "New Economy". A common perception was that the information technologies provided fundamentally new ways of organizing and conducting business. These technologies were believed to improve both current and future productivity. ${ }^{11}$ The proliferation of dotcoms and e-commerce was even "touted as a new industrial revolution" (Gordon (2003, p. 41)). However, expectations of high demand did not materialize in the case of on-line trading, and failed dotcoms became a legacy.

\section{Concluding remarks}

How important are surprise and anticipated changes (or news shocks) in TFP as a source of economic fluctuations? This question is answered in the paper by examining a particular historical episode: the U.S. boom and bust cycle in the 1995-2003 period. The findings confirm that optimistic expectations and their revisions may have been critical to understanding the episode.

The performance of the U.S. economy is evaluated through the lens of a spirit-of-capitalism model with both news and surprise TFP shocks. The paper estimates the productivity prospects, a measure that captures the effects of TFP news on economic decisions. The estimated productivity prospects are closely related to measures of consumer and investor confidence as well as to the medium term TFP projections. Changes in the productivity prospects forecast future measured productivity impulses at several horizons. The productivity prospects and empirical productivity shocks are used to construct counterfactual paths for the U.S. economy. The predictions of the model are largely in conformity with the observed hours worked, output, investment, consumption, real wages and stock prices during boom-bust cycle. The SOC model therefore provides a possible explanation for several unique and puzzling features of the 1995-2003 period.

\footnotetext{
${ }^{11}$ Lohr (1999) summarizes these rosy views of the future: "The Internet has become a powerful symbol of society's expectations about the future - a future of fast-moving, disruptive productivity that is shifting the terrain not only in business, but also in politics and culture... Because it is such a low-cost communications productivity, the Internet holds the promise of drastically reducing transactions costs."
} 


\section{Appendix A: Uniqueness of the 2001 recession}

Many researchers have acknowledged that the 2001 recession was unusual and that understanding investment behavior is the key to understanding the 2001 recession. The following quotations provide an illustration:

"The recession that began in the United States in March 2001 is distinctive in being one of the few business-led - as opposed to household-led - recessions of the post-World War II period. Typically, U.S. recessions have featured downturns in household spending, with housing and consumer durables being the most severely affected, and with business spending on capital goods playing a secondary and generally reactive role. In the recent episode, by contrast, business fixed investment began to weaken well before the official peak of the business cycle, contracting in real terms from the fourth quarter of 2000 through the third quarter of last year. In an arithmetic sense at least, this decline in investment accounted for a very substantial part of the general economic slowdown of the past few years. Meanwhile, completing the role reversal, households maintained their spending remarkably well, particularly on new homes and automobiles." (Bernanke (2003))

"The recession that began in March 2001 differed in many ways from other recessions of the past three decades.... In contrast, the recession of 2001 started neither in the shopping mall nor in the corridors of the Federal Reserve Bank, but in the boardrooms of corporate America as businesses sharply cut back on expenditures - most notably, investment associated with information technology - in turn leading to declines in manufacturing output and in the overall stock market." (Stock and Watson (2003, p. 71))

"In contrast to the post-war norm the expansion was not "murdered" by the Federal Reserve. The contraction started with an investment bust, as firms that had radically overinvested during the boom years of the late 1990s suddenly cut back." (The Economist (2001, p.26))

"The key point is that this isn't your father's recession - it's your grandfather's recession. That is, it isn't your standard postwar recession, engineered by the Federal Reserve to fight inflation, and easily reversed when the Fed loosens the reins. It's a classic overinvestment slump, of a kind that was normal before World War II." (Krugman (2002))

Based on the analysis of real-time forecasts from the Blue Chip Indicators, Kliesen (2003, p. 35) concluded that the unexpected decline in real business fixed investment was "perhaps the most significant shock that led to the 2001 recession."

The investment bust is often interpreted as resulting from a correction of investment decisions made during the preceding boom. For example, according to Ben Bernanke, at the time a member of the Board of Governors of the Federal Reserve System,

"As we can see, in retrospect at least, the year 2000 was one of re-evaluation, particularly for high-tech investment. Though the evidence is strong that high-tech investments have greatly enhanced technology in the economy, by 2000 many managers had apparently become concerned that the long-term profit potential of their investments in computers and communications equipment was smaller than they had expected. In some cases the difficulties were technological, sometimes (as in the case of on-line retailing) the expected level of consumer demand did not 
materialize, sometimes the business plans were faulty, sometimes economic or regulatory conditions were not as had been expected, and sometimes the productivity enhancements were less than anticipated." (Bernanke (2003, p. 5))

Similarly, William Poole, the president and chief executive officer of the Federal Reserve Bank of St. Louis, stated in 2002 that

"Business investment last year was driven by a reassessment of long-term prospects in certain sectors, especially telecom, and by adjustment to excess capacity resulting from the prior investment boom." (Poole (2002, p.12))

Downward revisions of previously optimistic expectations is the most common explanation for the decline in investment. The following three extracts from government publications serve as an illustration:

"A dramatic downturn shift in the rate of growth of business fixed investment and inventories was the primary cause of the recession.... Overly optimistic expectations of future growth in demand, which were reflected in inflated stock prices, led businesses to invest in new plant and equipment at levels that appear excessive in hindsight."

(The Congressional Budget Office (2001, p. 24))

"Some businesses, especially in the information and communications technology sector, may have overestimated the potential of the "New Economy" and therefore overinvested in productive capacity. In addition, businesses throughout the economy were surprised by the extent of the slowdown in aggregate demand in 2000 and 2001, and therefore had to revise downward the path of their desired capital stock."

(The Council of Economic Advisers (2002, p. 40))

"... the magnitude by which these categories of expenditure had increased in preceding years, together with abruptness of their downturn, suggests that firms may have been too optimistic about the immediate profitability of some types of high-tech capital; as these expectations were revised, business viewed their previous investment as more than sufficient to meet anticipated demand." (Board of Governors of the Federal Reserve System (2001, p. 15))

Finally, the U.S. investment boom of the late 1990s and the 2001 recession are often cited as a motivation to study news shocks as sources of business cycles. See, for example, Jaimovich and Rebelo (2009, pp. 1097-1099) and the following conclusion of Beaudry and Portier (2004, p. 1214):

"We also believe that the U.S. recession of 2001 may reflect a downturn of a Pigou cycle. ... what we believe to be the most important source of anticipation over this period, which eventually was revised downward in 2001, regarded the anticipated speed of discovery and development of new uses for IT goods. According, we believe that it was the expectation of such development that drove the investment process, whether it be in telecommunications, computers or structures; and it was the revision of this expectation that lead to a recession." 


\section{Appendix B: Application of Blanchard and Kahn's algorithm}

This Appendix explains how to derive the representation (19)-(20) using Blanchard and Kahn (1980)'s algorithm, denoted BK80 thereafter. Whenever possible, the notation follows BK80. The variables with the carets denote the percentage deviations from the steady state.

First, the equilibrium of the model is reduced to a system in terms of capital and consumption. The expected value of the productivity shock is included directly into a vector of exogenous variables $Z_{t}$.

$$
\begin{aligned}
{\left[\begin{array}{c}
\hat{k}_{t+1} \\
E_{t} \hat{c}_{t+1}
\end{array}\right] } & =\mathbf{A}\left[\begin{array}{l}
\hat{k}_{t} \\
\hat{c}_{t}
\end{array}\right]+\left[\begin{array}{l}
\gamma_{1} \\
\gamma_{2}
\end{array}\right] Z_{t}, Z_{t}=\left[\begin{array}{c}
\hat{z}_{t} \\
E_{t} \hat{z}_{t+1}
\end{array}\right] t>0 \\
\hat{k}_{t=0} & =\hat{k}_{0}
\end{aligned}
$$

where $\mathbf{A}=\left[\begin{array}{ll}a_{11} & a_{12} \\ a_{21} & a_{22}\end{array}\right], \gamma_{1}=\left[\begin{array}{ll}\gamma_{11} & 0\end{array}\right], \gamma_{2}=\left[\begin{array}{ll}\gamma_{21} & \gamma_{22}\end{array}\right]$. The entries of the matrices $\mathbf{A}, \gamma_{1}$ and $\gamma_{2}$ are non-linear functions of the model parameters. All other variables of the model are expressed as linear functions of $\hat{k}_{t}, \hat{z}_{t}$ and $\hat{c}_{t}$ :

$$
\hat{v}_{t}=\phi_{v k} \hat{k}_{t}+\phi_{v z} \hat{z}_{t}+\phi_{v c} \hat{c}_{t} .
$$

Let $\lambda_{1}$ and $\lambda_{2}$ denote the eigenvalue of the matrix $\mathbf{A}$, with $\left|\lambda_{1}\right|<1$ and $\left|\lambda_{2}\right|>1$. Following the formulas on p.1309 of BK80, the solution is written as

$$
\begin{aligned}
& \hat{k}_{t}=\hat{k}_{0}, \\
& \hat{k}_{t}=\lambda_{1} \hat{k}_{t-1}+\gamma_{1} Z_{t-1}+\sum_{j=0}^{\infty} \lambda_{2}^{-j-1} \mu E_{t-1}\left(Z_{t+j-1}\right), t>0, \\
& \hat{c}_{t}=a_{12}^{-1}\left[\left(\lambda_{1}-a_{11}\right) \hat{k}_{t}+\sum_{j=0}^{\infty} \lambda_{2}^{-j-1} \mu E_{t}\left(Z_{t+j}\right)\right], t \geq 0,
\end{aligned}
$$

where $\mu=\left(\lambda_{1}-a_{11}\right) \gamma_{1}-a_{12} \gamma_{2} \cdot{ }^{12}$ Partition the vector $\mu$ as $\mu=\left[\begin{array}{ll}\mu_{1} & \mu_{2}\end{array}\right]$, with $\mu_{1}=$ $\left(\lambda_{1}-a_{11}\right) \gamma_{11}-a_{12} \gamma_{21}$ and $\mu_{2}=-a_{12} \gamma_{22}$. The discounted sum of the expected future productivity shocks is expanded using the definition of $Z_{t}$, the law of motion for $\hat{z}_{t}$ and the conditional forecasts (15) as follows

$$
\begin{aligned}
& \sum_{j=0}^{\infty} \lambda_{2}^{-j-1} \mu E_{t}\left(Z_{t+j}\right)=\lambda_{2}^{-1} \mu_{1} \hat{z}_{t}+\sum_{j=1}^{\infty} \lambda_{2}^{-j}\left(\mu_{2}+\lambda_{2}^{-1} \mu_{1}\right) E_{t} \hat{z}_{t+j} \\
= & {\left[\lambda_{2}^{-1} \mu_{1}+\left(\mu_{2}+\lambda_{2}^{-1} \mu_{1}\right) \frac{\lambda_{2}^{-1} \rho}{1-\lambda_{2}^{-1} \rho}\right] \hat{z}_{t}+\frac{\mu_{2}+\lambda_{2}^{-1} \mu_{1}}{1-\lambda_{2}^{-1} \rho} \sum_{j=1}^{\infty} \lambda_{2}^{-j} E_{t} \varepsilon_{t+j} . }
\end{aligned}
$$

Using the definitions of $\gamma_{1}$ and $\theta_{t}$ and substituting the expression (33) into the formulas (31) and

\footnotetext{
${ }^{12}$ Note a typo in BK80: the values $\gamma_{1}$ and $\gamma_{2}$ instead of $\lambda_{1}$ and $\lambda_{2}$ should appear in the definition of $\mu$.
} 
(32) leads to the solution for $\hat{k}_{t}$ and $\hat{c}_{t}$,

$$
\begin{aligned}
& \hat{k}_{t}=M_{k k} \hat{k}_{t-1}+M_{k z} \hat{z}_{t-1}+M_{k \theta} \theta_{t-1}, t>0, \\
& \hat{c}_{t}=M_{c k} \hat{k}_{t}+M_{c z} \hat{z}_{t}+M_{c \theta} \theta_{t}, t \geq 0,
\end{aligned}
$$

where

$$
\begin{aligned}
M_{k k} & \equiv \lambda_{1}, M_{c k} \equiv a_{12}^{-1}\left(\lambda_{1}-a_{11}\right), \\
M_{k z} & \equiv \gamma_{11}+\lambda_{2}^{-1} \mu_{1}+\left(\mu_{2}+\lambda_{2}^{-1} \mu_{1}\right) \lambda_{2}^{-1} \rho /\left(1-\lambda_{2}^{-1} \rho\right), \\
M_{c z} & \equiv a_{12}^{-1}\left[\lambda_{2}^{-1} \mu_{1}+\left(\mu_{2}+\lambda_{2}^{-1} \mu_{1}\right) \lambda_{2}^{-1} \rho /\left(1-\lambda_{2}^{-1} \rho\right)\right] \\
M_{k \theta} & =\left(\mu_{2}+\lambda_{2}^{-1} \mu_{1}\right) /\left(1-\lambda_{2}^{-1} \rho\right), M_{c \theta}=a_{12}^{-1} M_{k \theta} .
\end{aligned}
$$

The other variables of the model are computed as follows

$$
\hat{v}_{t}=M_{v k} \hat{k}_{t}+M_{v k} \hat{z}_{t}+M_{v \theta} \theta_{t}
$$

with $M_{v k}=\phi_{v k}+\phi_{v c} M_{c k}, M_{x z}=\phi_{v z}+\phi_{v c} M_{c z}$ and $M_{v \theta}=\phi_{v c} M_{c \theta}$. 


\section{Appendix C: Data sources}

The data are obtained from several sources. The BEA stands for the Bureau of Economic Analysis. The BEA data used in the paper were published August 26, 2011. The BLS denotes the Bureau of Labor Statistics. FRED II refers to the FRED II database at the Federal Reserve Bank of St. Louis.

1. Real output $=$ gross domestic product for nonfarm business sector; BEA; NIPA table 1.3.3, line 3; quantity index, 2005=100; seasonally adjusted at annual rate.

2. Real consumption $=$ personal consumption expenditures; BEA; NIPA table 1.1.3, line 2; quantity index, 2005=100; seasonally adjusted at annual rate.

3. Real investment $=$ gross private domestic fixed investment; BEA; NIPA table 1.1.3, line 8; quantity index, 2005=100; seasonally adjusted at annual rate.

4. Price of consumption $=$ personal consumption expenditures; BEA; NIPA table 1.1.4, line 2; price index, 2005=100; seasonally adjusted at annual rate.

5. Price of investment $=$ gross private domestic fixed investment; BEA; NIPA table 1.1.4, line 8; quantity index, 2005=100; seasonally adjusted at annual rate.

6. Hours worked $=$ hours for nonfarm business sector; BLS; series PRS85006033; index, $2005=100$; downloaded September 2011.

7. Real wage $=$ real hourly compensation for nonfarm business sector. BLS, series PRS85006153; index, 2005 = 100; downloaded September 2011.

8. Capital services = capital services for private nonfarm business sector; BLS; Table XG1a "Net Multifactor Productivity and Costs, 1987 - 2010; Private Non-Farm Business Sector (Excluding Government Enterprises); Basic Measures"; levels; constant 2005 dollars; published May 19, 2011. The annual series is converted to quarterly by assuming a constant growth rate within each quarter.

9. Capital's share $=$ capital's share in cost for nonfarm business sector; Table XG4a, "Net Multifactor Productivity and Cost, 1948 - 2010; SIC 1948-87 linked to NAICS 1987-2010; Private Non-Farm Business Sector (Excluding Government Enterprises); Shares and Multifactor Measures"; levels; published May 19, 2011.

10. Population = civilian noninstitutional population over 16 years of age; FRED II; series CNP16OV; converted to quarterly data by taking monthly averages; published October 7, 2011.

11. Index of consumer sentiment $=$ the University of Michigan's index of consumer sentiment; FRED II; series UMCSENT; index, 1st quarter $1966=100$; converted to quarterly data by taking monthly averages; not seasonally adjusted; published September 8, 2011.

12. Real price of investment $=(5) /(4)$.

13. Stock price $=$ the Standard \& Poors 500 index (values at the closing), downloaded from Yahoo!Finance. ${ }^{13}$ The quarterly index is equal to monthly averages.

14. Real stock price $=(13) /(4)$.

15. The Gallup index of investor optimism = this index was known as UBS/Gallup index of investor optimism until 2008, the Gallup index of investor optimism and then the Wells Fargo/Gallup index of investor optimism. The index is based on the survey of investors, conducted between October 1996 until September 2011. Monthly data are available for all the months from February 1999 until December 2007. In other periods, the survey was not conducted every month. There are no observations for 2010 . The data for the index were collected from the online publications and can be sent upon the request. The quarterly series used in the paper is equated with the monthly index, if a single observation was reported in that quarter. Otherwise, the quarterly series is equal to the averages of the available monthly indices.

\footnotetext{
${ }^{13} \mathrm{http}: / /$ finance.yahoo.com $/ \mathrm{q} / \mathrm{hp} ? \mathrm{~s}=\% 5 \mathrm{EGSPC} \& \mathrm{a}=00 \& \mathrm{~b}=3 \& \mathrm{c}=1950 \& \mathrm{~d}=09 \& \mathrm{e}=5 \& \mathrm{f}=2011 \& \mathrm{~g}=\mathrm{m}$
} 


\section{References}

Bakshi, G. S., Chen, Z., 1996. The spirit of capitalism and stock-market prices. American Economic Review 86 (1), 133-157.

Barsky, R. B., Sims, E. R., 2011. News shocks and business cycles. Journal of Monetary Economics $58(3), 273-289$.

Beaudry, P., Lucke, B., 2010. NBER Macroeconomics Annual 2009, Volume 24. University of Chicago Press, Ch. Letting Different Views about Business Cycles Compete, pp. 413-455.

Beaudry, P., Portier, F., 2004. An exploration into Pigou's theory of cycles. Journal of Monetary Economics 51 (6), 1183-1216.

Beaudry, P., Portier, F., 2006. Stock prices, news, and economic fluctuations. American Economic Review 96 (4), 1293-1307.

Beaudry, P., Portier, F., 2007. When can changes in expectations cause business cycle fluctuations in neo-classical settings? Journal of Economic Theory 135 (1), 458-477.

Bernanke, B. S., 2003. Will business investment bounce back? Speech before the Forecasters Club April 24, New York.

Blanchard, O. J., Kahn, C. M., 1980. The solution of linear difference models under rational expectations. Econometrica 48 (5), 1305-1031.

Board of the Governors of the Federal Reserve System, April 2002. 88th Annual Report 2001. Tech. rep., Board of the Governors of the Federal Reserve System, Washington, D.C.

Christiano, L., Ilut, C., Motto, R., Rostagno, M., 2008. Monetary policy and stock market boombust cycles. Working Paper Series 955, European Central Bank.

Christiano, L., Motto, R., Rostagno, M., 2010. Financial factors in economic fluctuations. Working Paper Series 1192, European Central Bank.

Christiano, L. J., Eichenbaum, M., 1992. Current real-business-cycle theories and aggregate labormarket fluctuations. American Economic Review 82 (3), 430-450.

Congressional Budget Office, January 2001. The budget and economic outlook: Fiscal years 20022011. A report to the Senat and House committees on the budget, Congress of the United States, Congressional Budget Office, Washington, D.C.

Congressional Budget Office, January 2005. The budget and economic outlook: Fiscal years 20062015. Tech. rep., Congress of the United States, Congressional Budget Office, Washington, D.C.

Council of Economic Advisers, 2002. The Annual Report of the Council of Economic Advisers. United States Government Printing Office, Washington.

Couper, E. A., Hejkal, J. P., Wolman, A. L., 2003. Boom and bust in telecommunications. Federal Reserve Bank of Richmond Economic Quarterly 89 (4), 1-24. 
Economist, 2001. Another shot from Dr. Feelgood: Will the Fed's latest cut in the interest rate get the economy moving again? (June 28th), 26-27.

Freeman, R., 2008. When workers share in profits: Effort and responses to shirking. CEP Discussion Papers 0882, Centre for Economic Performance, London School of Economics.

Gordon, R. J., 2003. Hi-tech innovation and productivity growth: Does supply create its own demand? Working Paper 9437, National Bureau of Economic Research.

Hansen, G., Prescott, E. C., 1993. Did technology shocks cause the 1990-1991 recession? American Economic Review, Papers and Proceedings 83 (2), 280-286.

Himmelberg, C. P., Mahoney, J. M., Bang, A., Chernoff, B., 2004. Recent revisions to corporate profits: what we know and when we knew it. Current Issues in Economics and Finance (Mar).

Ireland, P. N., 2011. A New Keynesian perspective on the Great Recession. Journal of Money, Credit and Banking 43 (1), 31-54.

Jaimovich, N., Rebelo, S., 2009. Can news about the future drive the business cycle? American Economic Review 99 (4), 1097-1118.

Jermann, U. J., 1998. Asset pricing in production economies. Journal of Monetary Economics 41 (2), $257-275$.

Jermann, U. J., Quadrini, V., 2007. Stock martket boom and the productivity gains of the 1990s. Journal of Monetary Economics 54 (2), 413-432.

Karnizova, L., 2010. The spirit of capitalism and expectation-driven business cycles. Journal of Monetary Economics 57 (6), 739-752.

Khan, H., Tsoukalas, J., Sep. 2009. The quantitative importance of news shocks in estimated dsge models. Carleton Economic Papers 09-07, Carleton University, Department of Economics.

King, R. G., Rebelo, S. T., 1999. Resuscitating Real Business Cycles. In: Taylor, J. B., Woodford, M. (Eds.), Handbook of Macroeconomics. Vol. 1B of Handbooks in Economics, vol. 15. Elsevier, Amsterdam, pp. 927-1007.

Kliesen, K. L., 2003. The 2001 recession: How was it different and what developments may have caused it? The Federal Reserve Bank of St.Louis Review 85 (5), 23-38.

Krugman, P., October 2002. My economic plan. New York Times 4.

Kruse, D. L., Blasi, J. R., Park, R., 2008. Shared capitalism in the U.S. economy: Prevalence, characteristics, and employee views of financial participation in enterprises. Working Paper 14225, National Bureau of Economic Research.

Kurmann, A., Otrok, C., 2011. News shocks and the term structure of interest rates: A challenge for DSGE models. unpublished manuscript.

Lebow, D. E., Sheiner, L., Slifman, L., Starr, M., 1999. Recent trends in compensation practices. FEDS Working Paper 99-32, FEDS, availble at SSRN http://ssrn.com/abstract=186131. 
Leeper, E., Walker, T., January 2011. Information flows and news driven business cycles. Review of Economic Dynamics 14 (1), 55-71.

Lohr, S., 1999. The economy transformed, bit by bit. The New York Times 20 (December), C1.

Lorenzoni, G., 2006. Recent developments in business cycle theory: News, expectations and demand shocks. Rivista di Politica Economica 96 (2), 61-78.

McGrattan, E. R., Prescott, E. C., 2009. Technical appendix: Unmeasured investment and the puzzling U.S. boom in the 1990s. Staff Report 395, Federal Reserve Bank of Minneapolis.

McGrattan, E. R., Prescott, E. C., 2010. Unmeasured investment and the puzzling US boom in the 1990s. American Economic Journal: Macroeconomics 2 (4), 88-123.

Poole, W., 2002. The role of finance in the investment bust of 2001. Speech at the Annual Southwestern Finance Association Meeting March 8.

Schmitt-Grohé, S., Uribe, M., 2010. What's news in business cycles. unpublished manuscript, Columbia University.

Stock, J. H., Watson, M. W., 2003. How did leading indicator forecasts do during the 2001 recession? Federal Reserve Bank of Richmond Economic Quarterly 89 (3), 71-90.

Weber, M., 1905. The Protestant Ethic and the Spirit of Capitalism. Charles Scribners' and Sons (1958 translated edition), New York.

Xiao, W., 2004. Explaining speculative expansions. Contributions to Macroeconomics 4 (1), Article 7. 
Table 1: Projected Average Annual Growth of Potential Total Factor Productivity for Nonfarm Business Sector (in percent)

\begin{tabular}{|c|c|c|}
\hline Publication date & Projection period & Projected TFP growth rate \\
\hline August , 1998 ( p. 21) & $1997-2008$ & 0.9 \\
\hline July, 1999 ( p. 13) & 1998-2009 & 1.1 \\
\hline January, 2000 ( p. 44 ) & 1999-2010 & 1.4 \\
\hline January , 2001 ( p. 34 ) & 2001-2011 & 1.5 \\
\hline August, 2001 ( p. 41 ) & 2001-2011 & 1.4 \\
\hline January , 2002 ( p. 37) & 2002-2012 & 1.3 \\
\hline July, 2002 ( p. 44) & 2002-2012 & 1.2 \\
\hline January , 2003 ( p. 46 ) & 2003-2013 & 1.2 \\
\hline August , 2003 ( p. 47 ) & 2003-2013 & 1.3 \\
\hline January , 2004 ( p. 40 ) & 2004-2014 & 1.3 \\
\hline September, 2004 ( p. 38 ) & 2004-2014 & 1.4 \\
\hline January, 2005 ( p. 45 ) & $2005-2015$ & 1.4 \\
\hline August, 2005 ( p. 43 ) & $2005-2015$ & 1.4 \\
\hline January, 2006 ( p. 44 ) & $2006-2016$ & 1.4 \\
\hline August, 2006 ( p. 35 ) & 2006-2016 & 1.5 \\
\hline January, 2007 ( p. 41) & $2007-2017$ & 1.4 \\
\hline August , 2007 ( p. 40 ) & $2007-2017$ & 1.4 \\
\hline January , 2008 ( p. 42 ) & 2008-2018 & 1.4 \\
\hline September, 2008 ( p. 45 ) & $2008-2018$ & 1.4 \\
\hline August, 2009 ( p. 45 ) & 2009-2019 & 1.4 \\
\hline
\end{tabular}

Source: Congressional Budget Office, The Budget and Economic Outlook, various issues. 
Table 2: Forecasting Power of Changes in Productivity Prospects for Productivity Impulses

\begin{tabular}{r|rrr|rrr}
\hline \hline Lag & \multicolumn{3}{|c}{$1983: 2-2010: 4$} & \multicolumn{3}{c}{$1983: 2-2007: 2$} \\
$j$ & $b_{j}$ & $(p$-value $)$ & $\bar{R}^{2}$ & $b_{j}$ & $(p$-value $)$ & $\bar{R}^{2}$ \\
\hline 7 & -0.098 & $(0.0307)$ & 0.036 & -0.112 & $(0.0115)$ & 0.060 \\
9 & -0.142 & $(0.0020)$ & 0.083 & -0.138 & $(0.0018)$ & 0.098 \\
21 & 0.125 & $(0.0125)$ & 0.059 & 0.080 & $(0.1086)$ & 0.022 \\
24 & -0.061 & $(0.2425)$ & 0.005 & -0.107 & $(0.0503)$ & 0.040 \\
27 & 0.147 & $(0.0044)$ & 0.085 & 0.117 & $(0.0489)$ & 0.043 \\
\hline \hline
\end{tabular}

Notes: The table reports the regression coefficients $b_{j}$, their marginal significance and the $\bar{R}^{2}$ statistics for the predictability regressions (28). 
Figure 1. The productivity estimates (1983:1-2010:4)

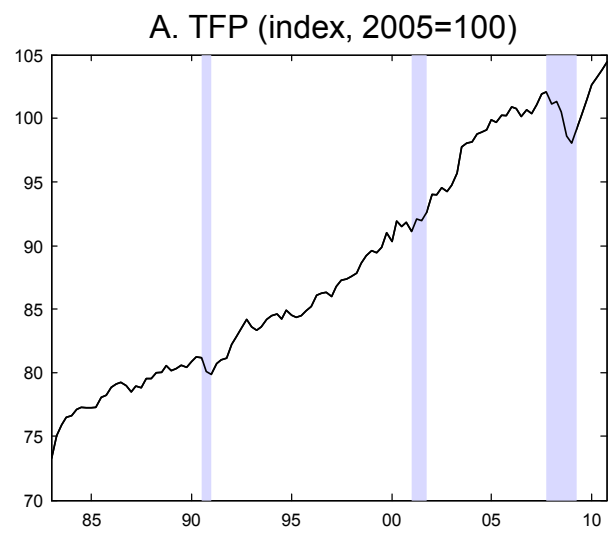

B. Measured TFP Shocks

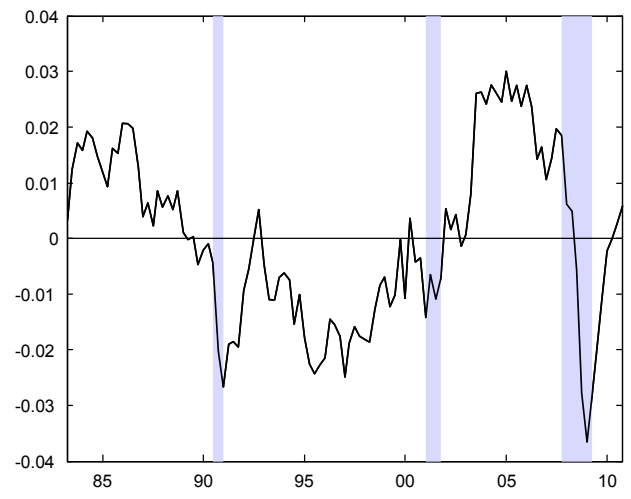

C. Measured TFP Impulses

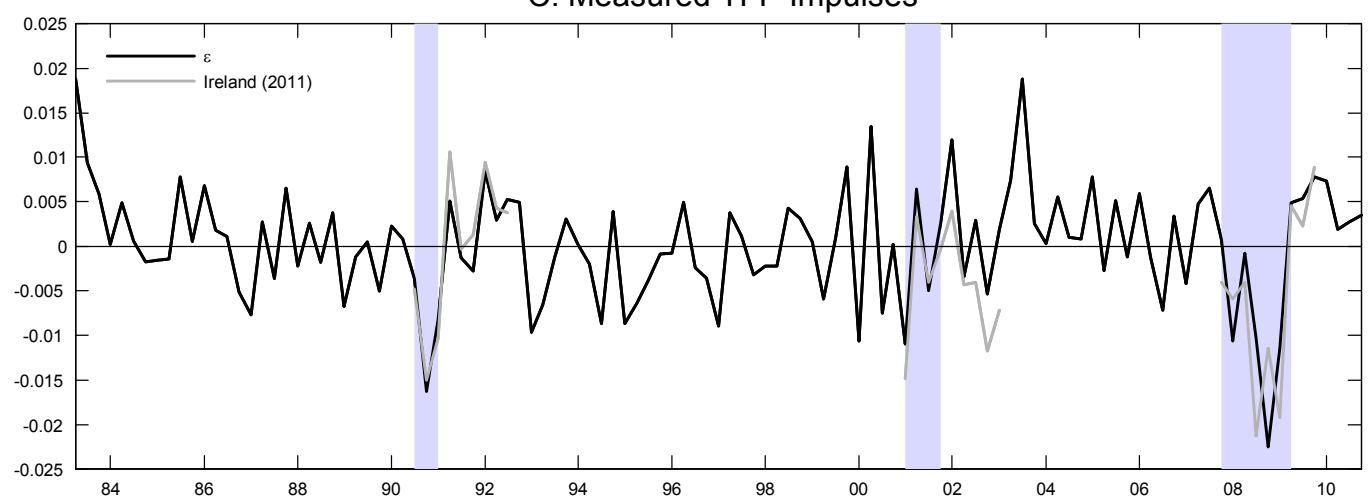

Notes: The data construction is explained in the section 3.1. The shaded areas indicate the NBER recession dates. 
Figure 2. Responses to a surprise productivity shock
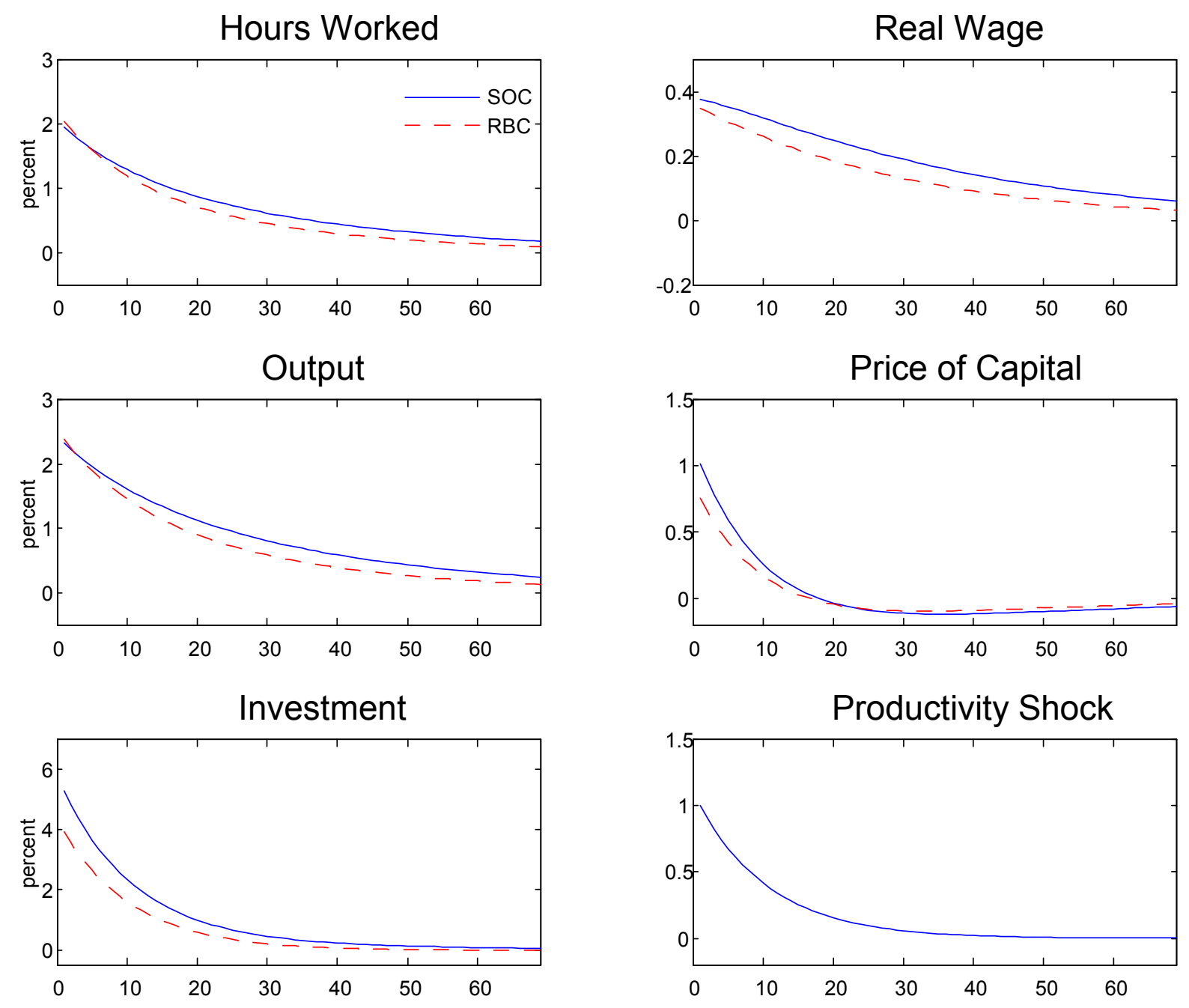

Consumption

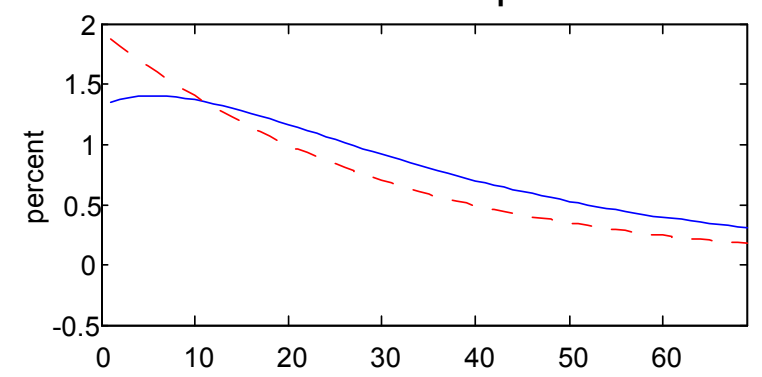

Notes: All variables are expressed in percentage deviations from the steady state. 'SOC' stands for the spirit of capitalism model. 'RBC' denotes the real business cycle model with capital adjustment costs parameter $\phi=0.802$ and the preference parameters $\omega=0$ and $\sigma=0.185$. The impulse responses are somewhat different from those reported by Karnizova (2010) due to a higher persistence of the productivity shock $\rho=0.979$ used in that study. 
Figure 3. Counterfactual and actual paths for aggregate quantities

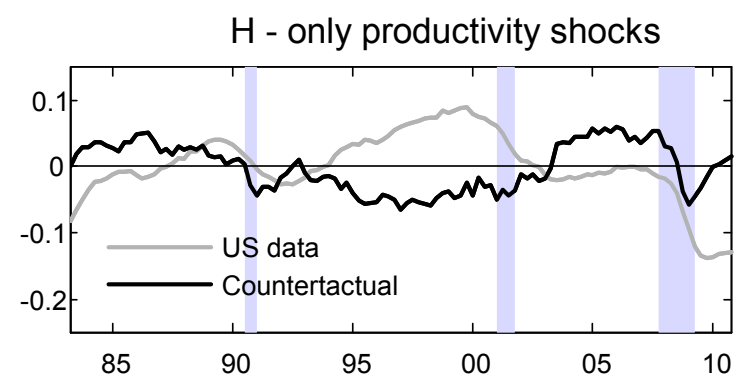

$\mathrm{H}$ - productivity shocks and prospects

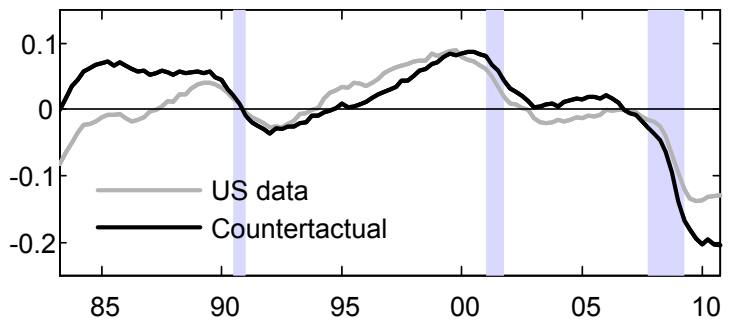

Y - only productivity shocks
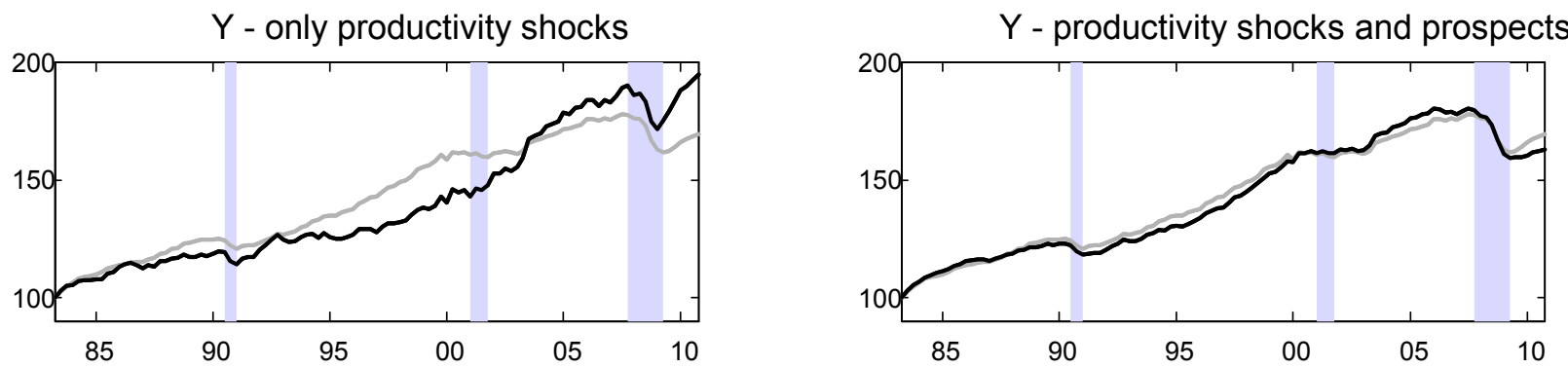

I - only productivity shocks

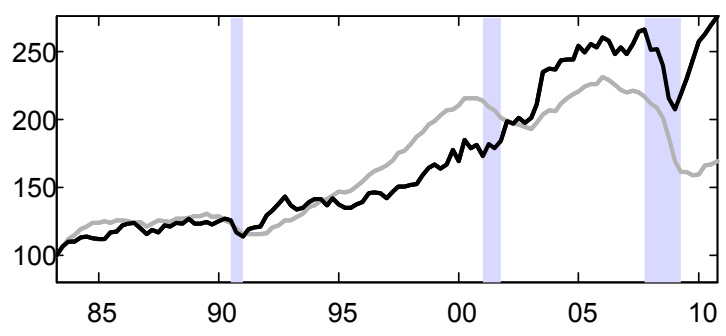

I - productivity shocks and prospects

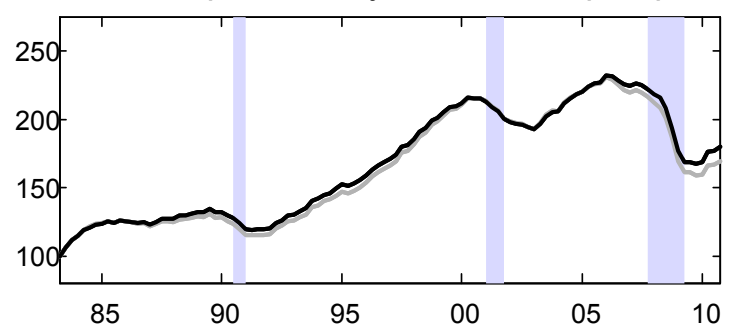

C - only productivity shocks
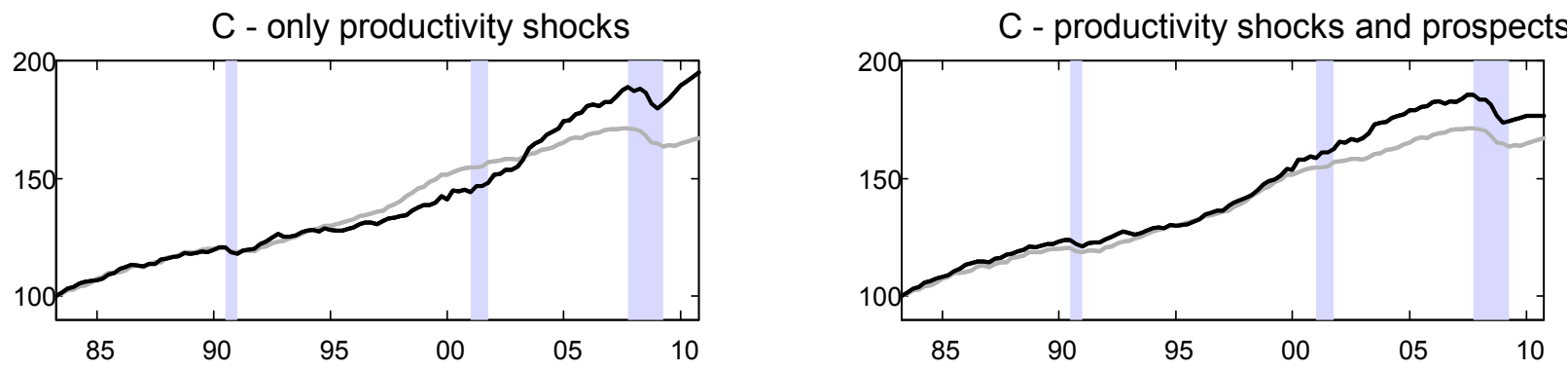

Notes: The gray lines are the actual U.S. data. The black lines are the predictions of the SOC model simulated with the measured productivity shocks only (the left column) or with the productivity shocks and productivity prospects (the right column). Hours are in percentage deviations from the sample mean. The other series are in levels, normalized to 100 in 1983:2. 
Figure 4. Counterfactual and actual paths for aggregate quantities during the recessions
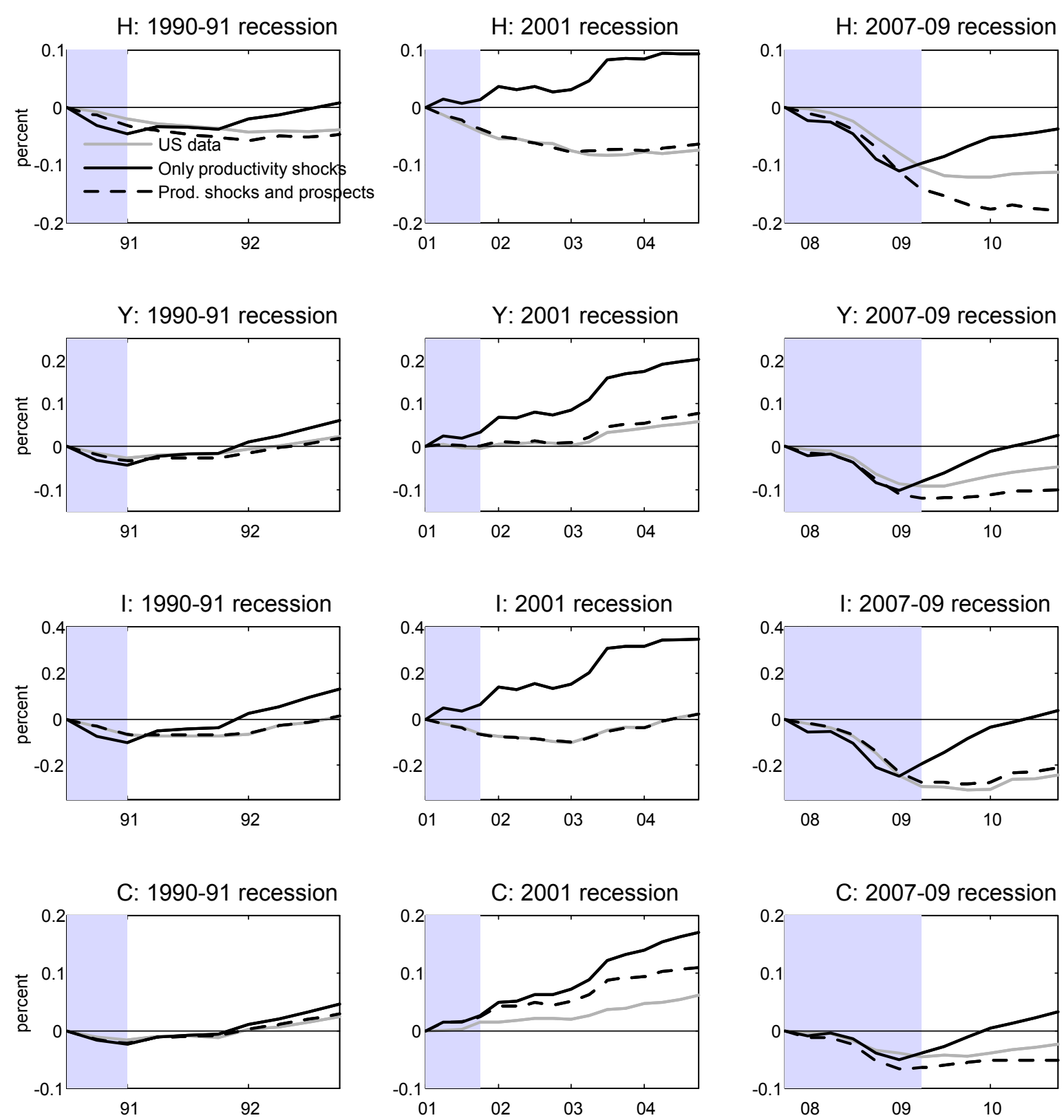

Notes: The gray lines correspond to the actual U.S. data. The black lines represent the series predicted by the SOC model simulated with the measured productivity shocks only (the solid lines) or with the productivity shocks and productivity prospects (the dotted lines). Both the actual and counterfactual paths are expressed as percentage deviations from the level achieved at the previous NBER cyclical peak. The shaded areas indicate the NBER recession dates. 
Figure 5. Responses to good news about productivity followed by no productivity change
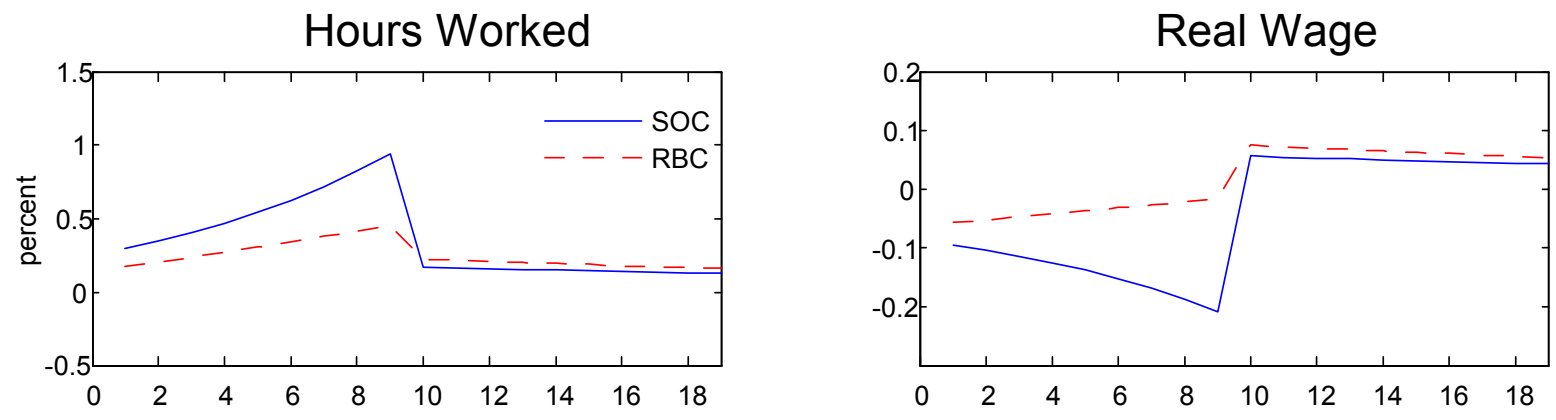

Output

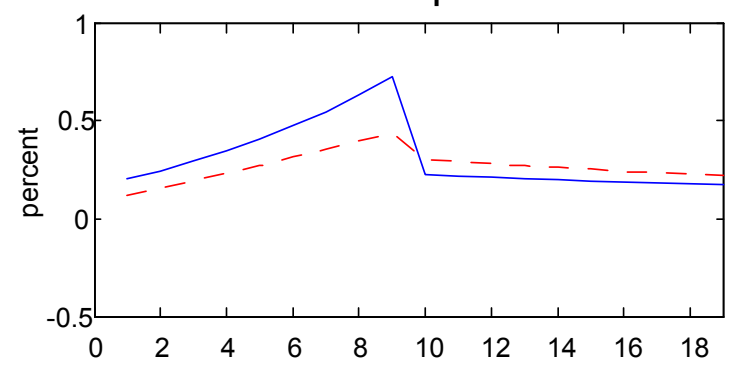

Investment

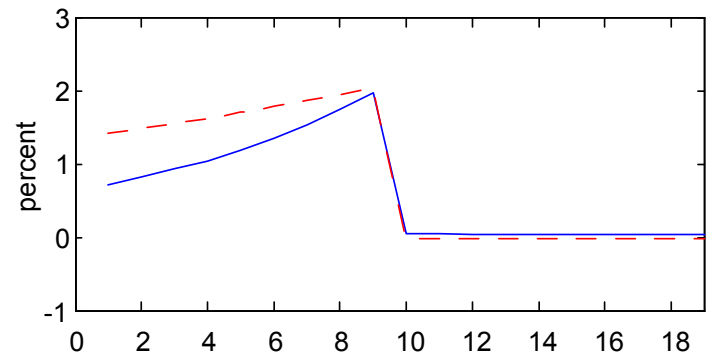

Consumption

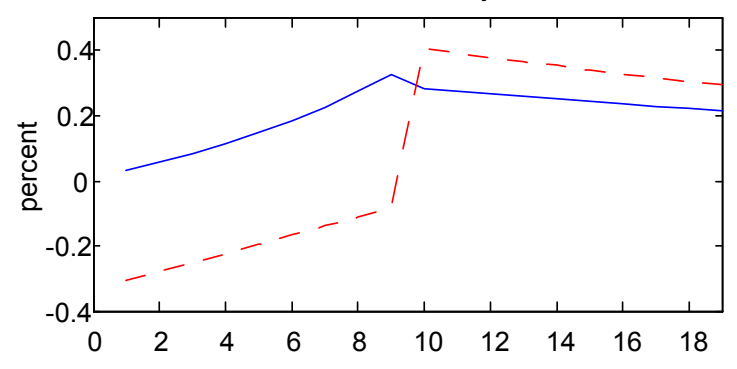

Price of Capital

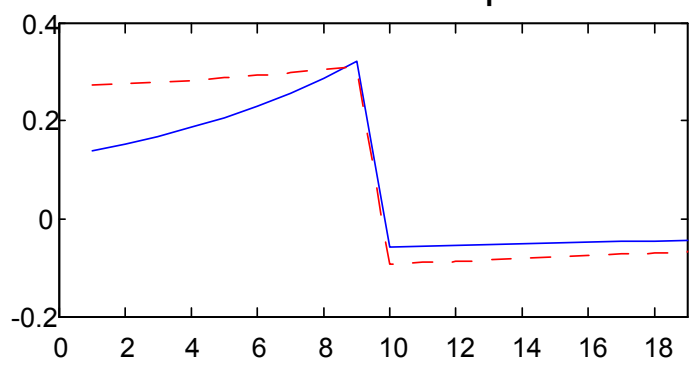

Productivity Shock

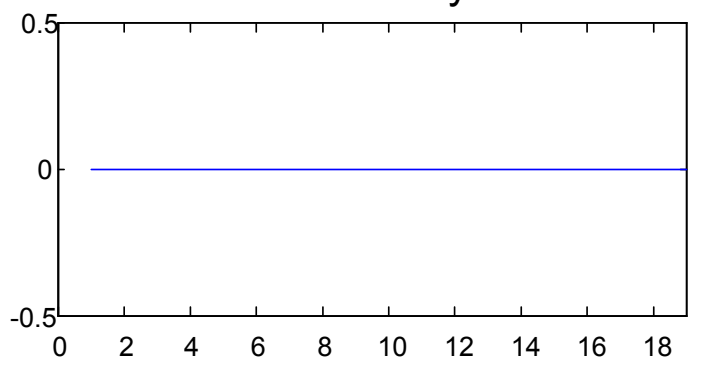

Notes: In period one there is an announcement that an aggregate technology shock of one percent will occur in period ten. This shock is not realized in period ten. All variables are in percentage deviations from the steady state. 'SOC' stands for the spirit of capitalism model. 'RBC' denotes the real business cycle model with capital adjustment costs parameter $\phi=0.802$ and the preference parameters $\omega=0$ and $\sigma=0.185$. 
Figure 6. Estimated productivity prospects and indices of measured expectations
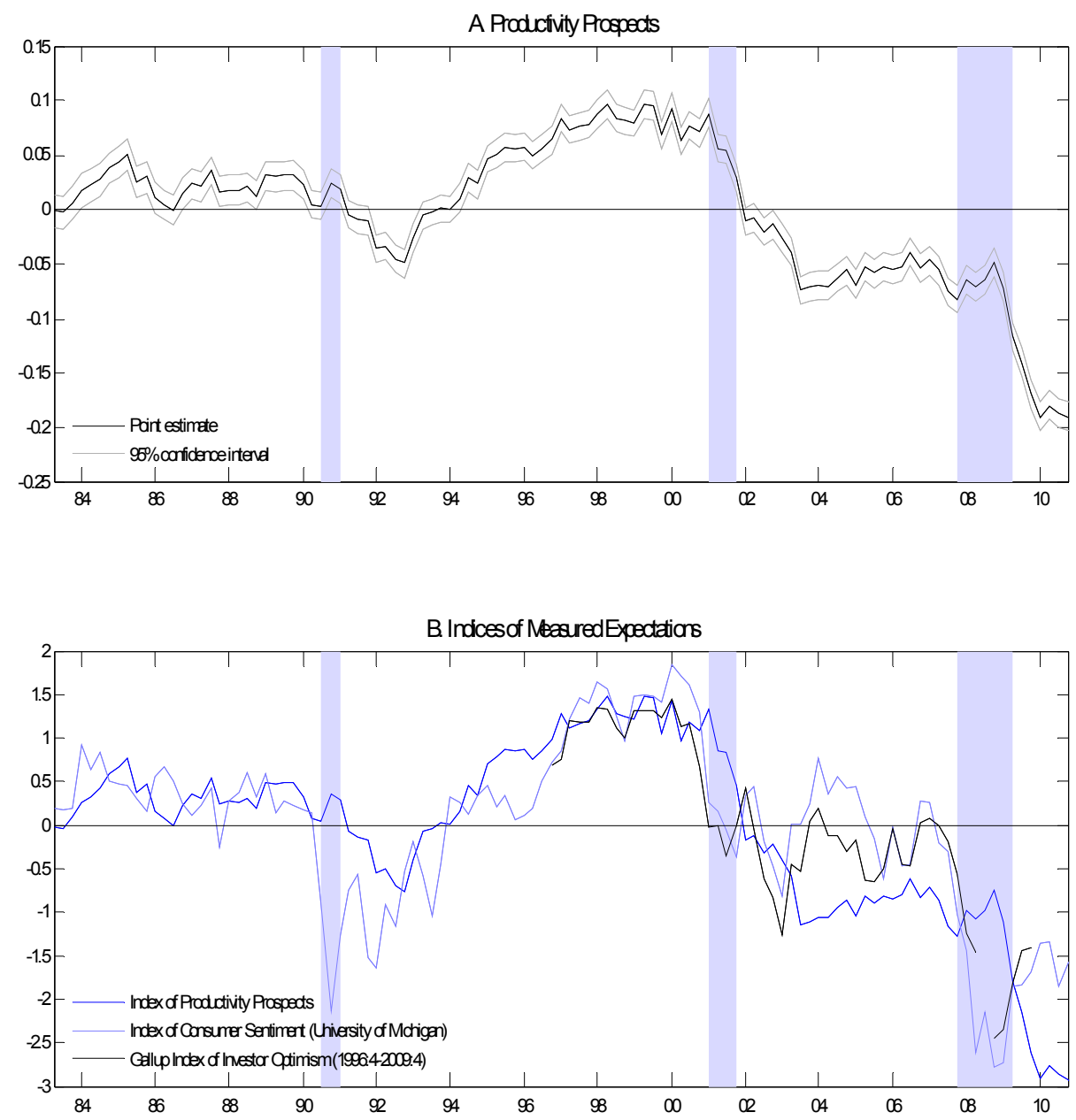

Notes: The solid black line represents the point estimates of the technology prospects based on the pooled regression model (27). The grey lines in panel A correspond to the $95 \%$ asymptotic confidence intervals. All measures of expectations on panel B are standardized. The shaded areas indicate the NBER recession dates. 
Figure 7. Dynamic correlations between $\varepsilon_{t}$ and $\Delta \theta_{t+j}$

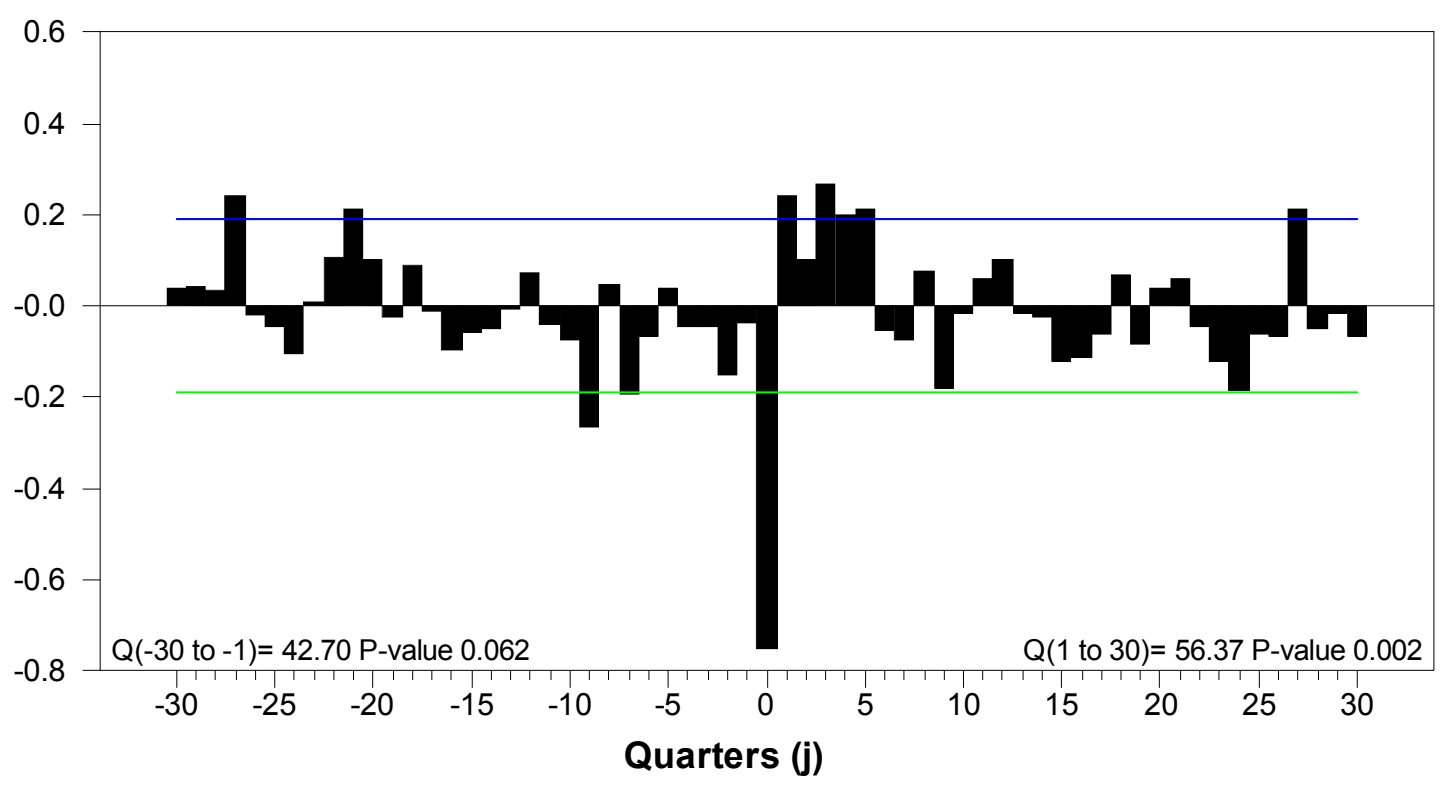

Notes: Each bar corresponds to a correlation coefficient between $\varepsilon_{t}$ and $\Delta \theta_{t+j}$. Under a null hypothesis of no correlation at any lag or lead, the asymptotic variance of each of the correlation estimates is $1 / \mathrm{T}$. The straight lines correspond to two standard deviations error bands. The value $Q(l$ to $m)$ is the Ljung-Box $Q$ statistics for a null hypothesis of nor correlation at the values $j$ from $l$ to $m$. The $P$-value indicates the significance level of the corresponding statistics. 
Figure 8. Counterfactual and actual paths for prices
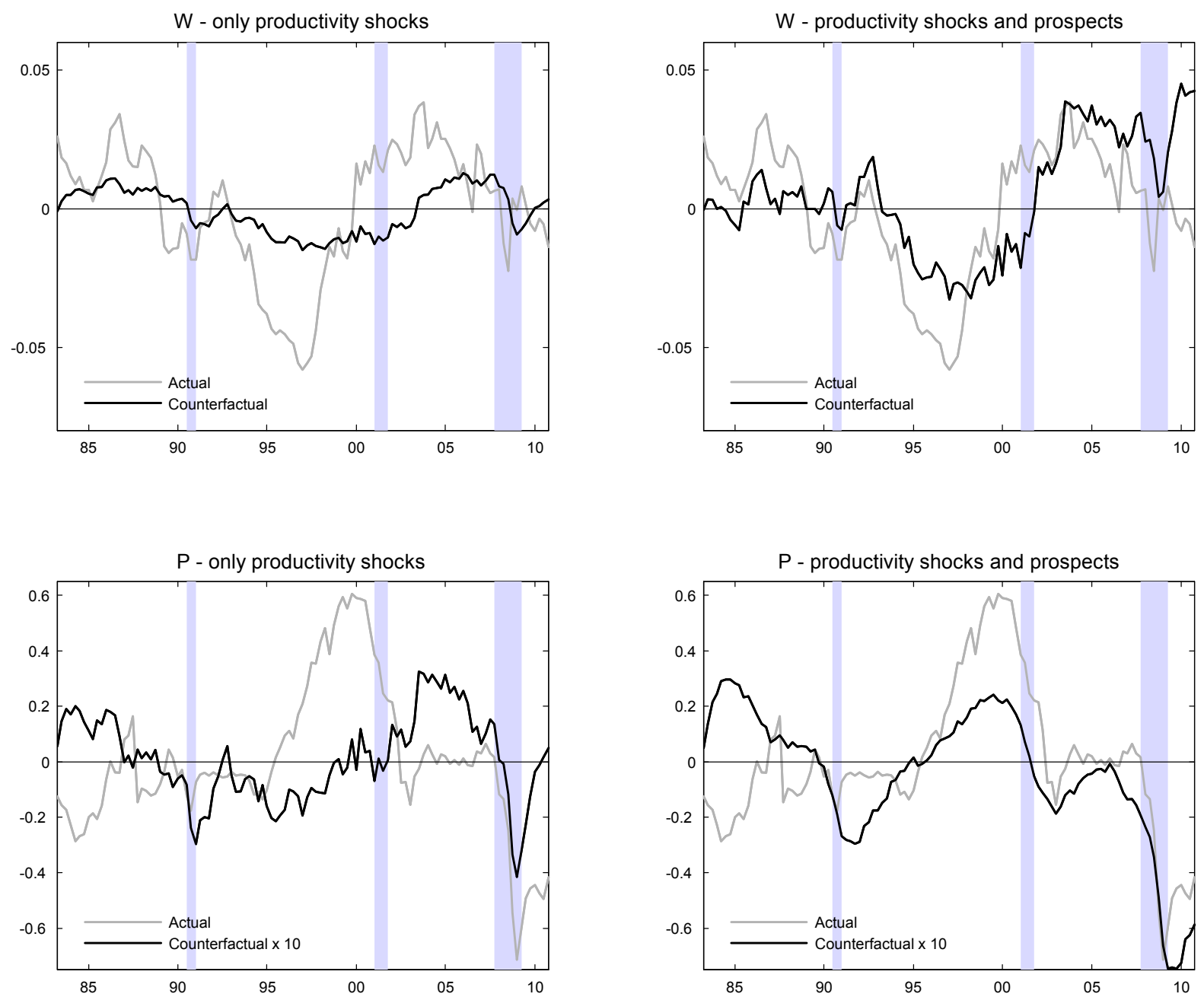

Notes: The gray lines are the actual U.S. data. The black lines are the series predicted by the SOC model simulated with the measured productivity shocks only (the left column) or with the productivity shocks and productivity prospects (the right column). The data are expressed in percentage deviations from the linear trend. The predicted values for the price of capital are multiplied by ten. The shaded areas indicate the NBER recession dates. 